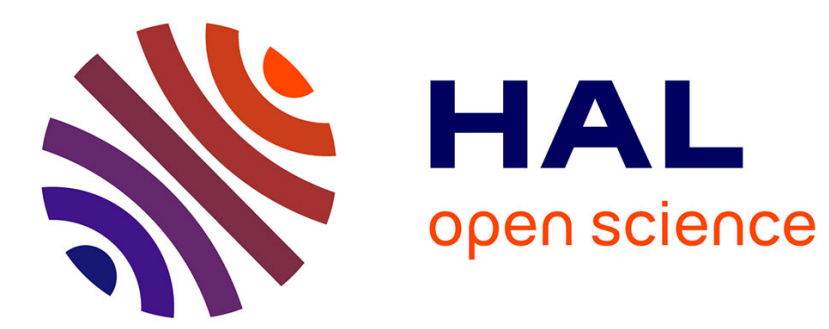

\title{
CRYSTAL-FIELD EFFECTS ON HIGH-SPIN FERROUS ION
}

F. Varret

\section{To cite this version:}

F. Varret. CRYSTAL-FIELD EFFECTS ON HIGH-SPIN FERROUS ION. Journal de Physique Colloques, 1976, 37 (C6), pp.C6-437-C6-456. 10.1051/jphyscol:1976688 . jpa-00216799

\section{HAL Id: jpa-00216799 https://hal.science/jpa-00216799}

Submitted on 1 Jan 1976

HAL is a multi-disciplinary open access archive for the deposit and dissemination of scientific research documents, whether they are published or not. The documents may come from teaching and research institutions in France or abroad, or from public or private research centers.
L'archive ouverte pluridisciplinaire HAL, est destinée au dépôt et à la diffusion de documents scientifiques de niveau recherche, publiés ou non, émanant des établissements d'enseignement et de recherche français ou étrangers, des laboratoires publics ou privés. 


\title{
CRYSTAL-FIELD EFFECTS ON HIGH-SPIN FERROUS ION
}

\author{
F. VARRET
}

Centre Universitaire du Mans, 72000 Le Mans, France

\begin{abstract}
Résumé. - Diverses méthodes permettent de résoudre le Hamiltonien électronique de l'ion ferreux soumis à un champ cristallin, lorsque seul le terme fondamental ${ }^{5} \mathrm{D}$ de l'ion libre intervient. Nous exposons la méthode la plus générale et indiquons quelques effets du champ cristallin sur les interactions hyperfines spontanées ou induites. Nous passons en revue des travaux récents ayant pour but de déterminer le schéma des niveaux de champ cristallin dans des composés variés, et comparons les valeurs obtenues pour les paramètres intervenant dans le modèle : $\lambda,\left\langle r^{-3}\right\rangle_{3 \mathrm{~d}}$, $A S, \Delta E_{0}$. Nous indiquons quelques composés pour lesquels les hypothèses de base : champ cristallin indépendant du temps et de la température, relaxation rapide, ne sont pas valides.
\end{abstract}

Abstract. - To treat the electronic Hamiltonian of the ferrous ion in a crystalline field, when only the high spin $5 \mathrm{D}$ term is concerned, several methods may be used. We describe the most general one, and indicate some effects of the crystal-field upon the spontaneous or induced hyperfine interactions. We review recent work aiming to determine crystal-field level schemes, and compare the values given for the relevant parameters : $\lambda,\left\langle r^{-3}\right\rangle_{3 \mathrm{~d}}, A S, \Delta E_{0}$. We also describe a few systems for which the basic assumptions - time and temperature independent crystal field, fas relaxation - are not fulfilled.

1. Introduction. - The physical basis of the crystalfield model has been described by several authors in books mostly devoted to the electron paramagnetic resonance and to the magnetic properties of the transition ions [1]. We do not describe it again, and restrict ourselves to the Mössbauer studies of the ferrous ion in the ${ }^{5} \mathrm{D}$ manifold.

The Mössbauer effect usually provides information on the electronic level scheme of $\mathrm{Fe}^{2+}$ in the crystalfield approach. In some cases low-temperature measurements allows the electronic ground-state to be determined [2-5]. By using both low-temperature Mössbauer data and direct measurements, such as EPR, IR, Raman, optical spectroscopies, the level scheme can be completely determined: an early example is that of $\mathrm{Fe}^{2+}$ in $\mathrm{ZnF}_{2}$ and $\mathrm{FeF}_{2}$ [4]. Magnetic data also are useful for this determination.

When only Mössbauer data are available, additional information is needed and may come from the thermal dependence of the hyperfine interactions [6]. The assumption of a temperature independent crystal field is then required. Following previous works [6-8], this theory has been applied to many ferrous compounds, often successfully. In the present study, we review recent work dealing with crystal field effects on the high-spin ferrous ion. We also describe the general calculation in the ${ }^{5} \mathrm{D}$ manifold, and outline the various difficulties occuring in the development of crystal-field studies.

2. Crystal field calculations in the ${ }^{5} D$ manifold. The basic assumptions are the following :

(i) The crystal field approach is valid, i. e. cova- lency is weak. This assumption holds fairly well in the case of oxides, halogenides, for which covalency effects are easily accounted for by a slight decrease in the orbital operators [1].

(ii) Only the ${ }^{5} \mathrm{D}$ term $(L=2, S=2)$ is involved, in agreement with Hund's rule (weak crystalline field).

A general calculation can be worked out by using the equivalent operator method [9]. The development of the crystalline potential in operators $O_{n}^{m}(\mathbf{L})$ is restricted to those which respect the point symmetry of the iron site ; in addition, since $d$ electrons are involved, the terms with $n>4$ or $n$ odd have null matrix elements (these developments for various point groups are tabulated in [10]). Consequently, the crystalline electronic Hamiltonian may be written as follows, with Hutchings' notations [11] :

$$
\begin{gathered}
\text { (i) } \mathscr{H}_{\mathrm{c}}^{\text {trig }}=B_{2}^{0} O_{2}^{0}+B_{4}^{0} O_{4}^{0}+B_{4}^{3} O_{4}^{3} \\
(O z=\text { three-fold axis }), \\
\text { (ii) } \mathscr{H}_{\mathrm{c}}^{\text {tetrag }}=B_{2}^{0} O_{2}^{0}+B_{4}^{0} O_{4}^{0}+B_{4}^{4} O_{4}^{4} \\
(O z=\text { four-fold axis }), \\
\text { (iii) } \mathfrak{H}_{\mathrm{c}}^{\text {rhomb }}=\mathfrak{H}_{\mathrm{c}}^{\text {tetrag }}+B_{2}^{2} O_{2}^{2}+B_{4}^{2} O_{4}^{2} \\
\left(O_{z}=\text { two-fold axis }\right),
\end{gathered}
$$

where $O z$ is the quantization axis. The matrix elements of the $O_{n}^{m}(\mathbf{L})$ in the standard basis $|L, L z\rangle$ have been tabulated by Hutchings [11]. The $B_{n}^{m}$ coefficients are expressed as

$$
\theta_{n} A_{n}^{m}<r^{n}>_{3 \mathrm{~d}}
$$


where the $A_{n}^{m}$ are summations of electric charges over the lattice ; $\theta_{2}$ and $\theta_{4}$ are equal to $-2 / 21$ and $2 / 63$ respectively; $\left\langle r^{2}\right\rangle_{3 d}$ and $\left\langle r^{4}\right\rangle_{3 d}$ have been computed for the free ion by using Hartree-Fock calculation data [12] and are $1.5 \mathrm{~A}$. U. and $5.4 \mathrm{~A}$. U. respectively. Usually the $B_{n}^{m}$ calculated in the point charge model do not fit the experimental data [13]; consequently, the $B_{n}^{m}$ are considered as phenomenological parameters to be determined from experimental studies.

Convenient forms for $\mathscr{H}_{\mathrm{c}}$ are the following [14] :

$$
\begin{aligned}
& \mathscr{H}_{c}^{\mathrm{trig}}=B_{4}^{3}\left[O_{4}^{3}-(\sqrt{2} / 40) O_{4}^{0}\right]+B_{2}^{0} O_{2}^{0}+ \\
& +\left[B_{4}^{o}+(\sqrt{2} / 40) B_{4}^{3}\right] O_{4}^{0} \\
& \mathfrak{H e}_{c}^{\text {tetrag }}=B_{4}^{4}\left[O_{4}^{4}+(1 / 5) O_{4}^{0}\right]+B_{2}^{0} O_{2}^{2}+ \\
& +\left[B_{4}^{0}-B_{4}^{4} / 5\right] O_{4}^{0} \\
& \mathcal{H}_{\mathrm{c}}^{\mathrm{rhomb}}=\mathcal{H}_{\mathrm{c}}^{\mathrm{tetrag}}+\mathrm{B}_{2}^{0} \mathrm{O}_{2}^{0}+\mathrm{B}_{4}^{2} \mathrm{O}_{4}^{2} \text {, }
\end{aligned}
$$

where the first term of each expression respects the cubic symmetry and for which the orientations of the $O x, O y, O z$ axes are given in figure 1. The present
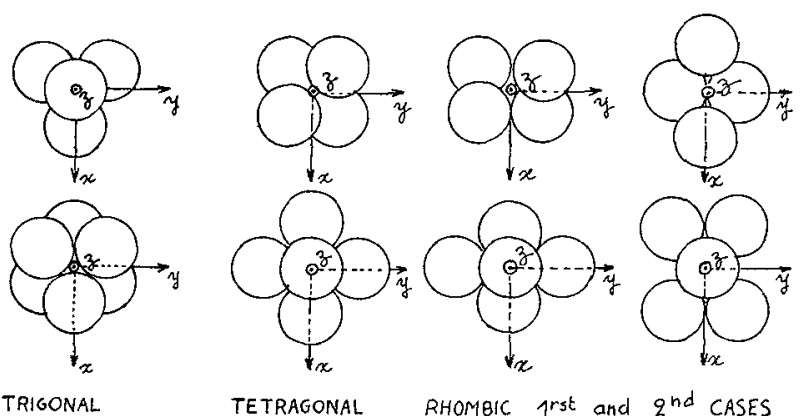

FIG. 1. - Orientations of the $O x y z$ axes suited to the expressions of $\mathcal{H}_{\mathrm{c}}$ given in the text, for various symmetries.

expressions are useful in most cases, since the surroundings often show only small departures from cubic symmetry. Other expressions for $\mathcal{H}_{\mathrm{c}}$ may be written ; the advantage of those shown is to give axial symmetry to the non-cubic terms (as was done by Ingalls [6]).

The cubic orbital splitting, $10 \mathrm{D}_{\mathrm{q}}$, is then given by :

$$
\begin{aligned}
10 \mathrm{D}_{\mathrm{q}} & =-(9 \sqrt{2} / 2) B_{4}^{3} & & \text { in the trigonal case } \\
& =-24 B_{4}^{4} & & \text { in the tetragonal case . }
\end{aligned}
$$

The orbital splittings due to $\mathscr{H}_{c}$ are shown on figure 2, where a positive $B_{2}^{0}$ was assumed. First-order calculations of the splittings due to the $B_{2}^{0}$ term are given in table $I$ : the corresponding wavefunctions were given previously [15]. Starting from the « pure » levels indicated in table $\mathrm{I}$, the following mixings are possible :

(i) $|0\rangle=d_{z^{2}}, \quad(|2>+|-2>) / \sqrt{2}=d_{x^{2}-y^{2}}$ through the $B_{2}^{2}, B_{4}^{2}$ terms (rhombic cases).

(ii) the trigonal doublets through $B_{2}^{0}, B_{4}^{0}$ (analytic expression given in sec. 4.5 and ref. [15]).

Additional remarks. - In principle, two rhombic cases have to be considered, according to the relative orientations of the two-fold axes and cubic four-fold axes : if these axes have the same orientations (Fig. 1c) the present expression of $\mathfrak{H}_{\mathbf{c}}^{\text {rhomb }}$ applies ; if these axes have different orientations (Fig. 1d) a rotation by $\pi / 4$ of the cubic term is needed. This rotation interchanges the $(12>+1-2>) / \sqrt{2}=d_{x^{2}-y^{2}}$ and $(|2>-|-2>) / \sqrt{2}=d_{x y}$ levels. Consequently the $d_{z^{2}}-d_{x^{2}-y^{2}}$ level mixing has different effects in the two rhombic cases, as follows :

(i) 1rst rhombic case (Fig. 1c) : the orbital levels of $\Gamma_{5}$ are pure $d_{x y}, d_{y z}, d_{x z}$ states (as in the tetragonal case); the orbital levels of $\Gamma_{3}$ are mixed together.

(ii) 2nd rhombic case (Fig. 1d): $\Gamma_{3}-\Gamma_{5}$ mixing; the $\Gamma_{5}$ levels are $d_{x z}, d_{y z},\left(d_{x^{2}-y^{2}}+\varepsilon d_{z^{2}}\right)$; the $\Gamma_{3}$ levels are $d_{x y},\left(d_{z^{2}}-\varepsilon d_{x^{2}-y^{2}}\right)$.

As a matter of fact, the right choice between the two rhombic cases may have some influence, but can be neglected when only a crude model is sought.

In addition, in the trigonal and tetragonal cases, the $O x O y$ axes should be correctly oriented (according to Fig. 1 when the present expressions of $\mathscr{H}_{\mathrm{c}}$ are used), since a basal anisotropy is expected, as shown in the case of $\mathrm{FeCr}_{2} \mathrm{O}_{4}$ [18]. In Mössbauer analyses, this basal anisotropy essentially concerns the magnetically induced effects (sec. 3.2, 3.4), and may be negligible when the orbital splittings are large enough; since this is often the case, one may usually forget the basal anisotropy and give to $O x$ any arbitrary orientation in the plane. Therefore the trigonal and tetragonal cases are commonly called « axial cases ».
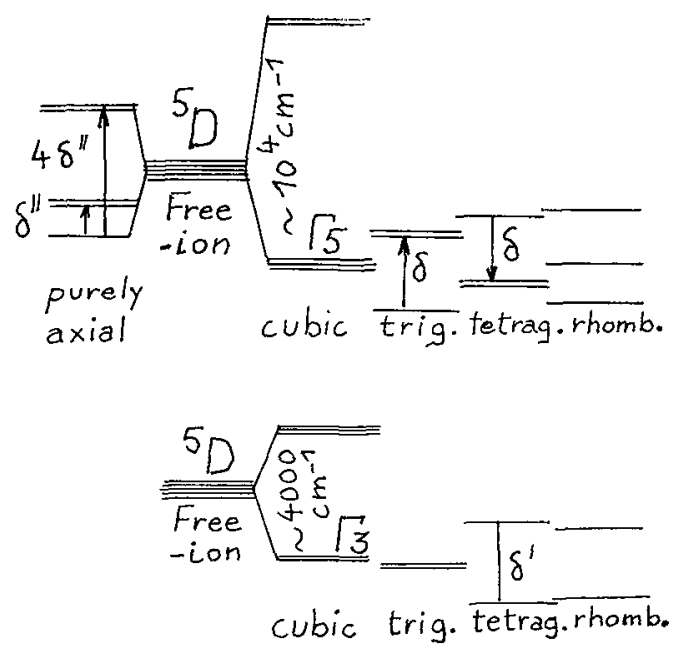

FIG. 2. - Orbital splittings in the $5 \mathrm{D}$ multiplet.

By introducing the spin interactions, the electronic Hamiltonian becomes:

$$
\begin{aligned}
& \mathscr{H}=\mathscr{H}_{\mathrm{c}}+\lambda \mathbf{L} . \mathbf{S}-\rho\left[(\mathbf{L} . \mathbf{S})^{2}+\left(\frac{1}{2}\right) \mathbf{L} . \mathbf{S}-\right. \\
& \begin{array}{c}
\left.-\left(\frac{1}{3}\right) L(L+1) S(S+1)\right] \\
+\mu_{\mathrm{B}} \mathbf{H}_{\mathrm{app}} \cdot(\mathbf{L}+2 \mathbf{S}),
\end{array}
\end{aligned}
$$

where $\lambda$ and $\rho$ are respectively $\sim-100 \mathrm{~cm}^{-1}$ and $+1 \mathrm{~cm}^{-1}$ in the free ion. The $\rho$-term cannot be neglect- 
CRYSTAL-FIELD EFFECTS ON HIGH-SPIN FERROUS ION

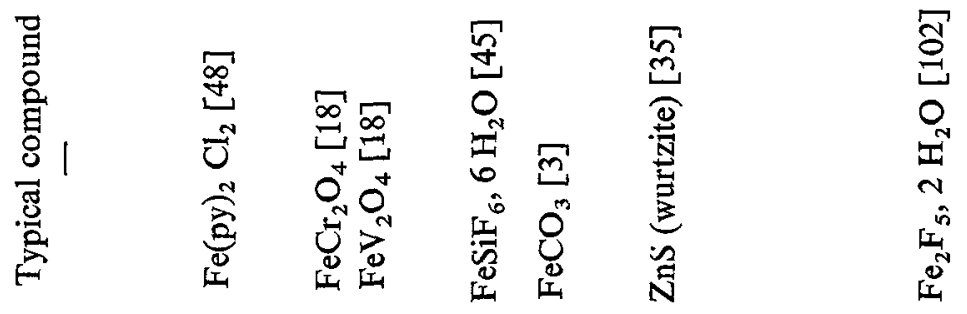

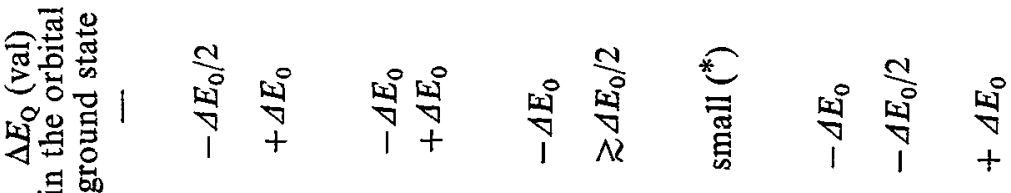

ค.$\exists$

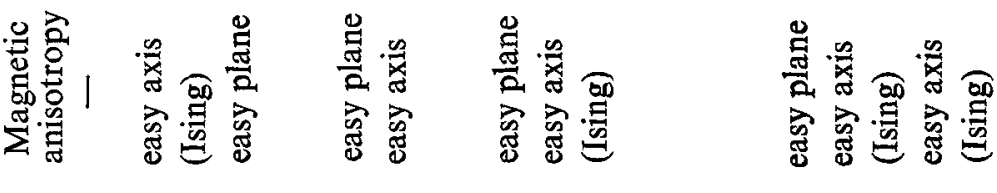

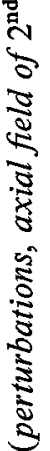
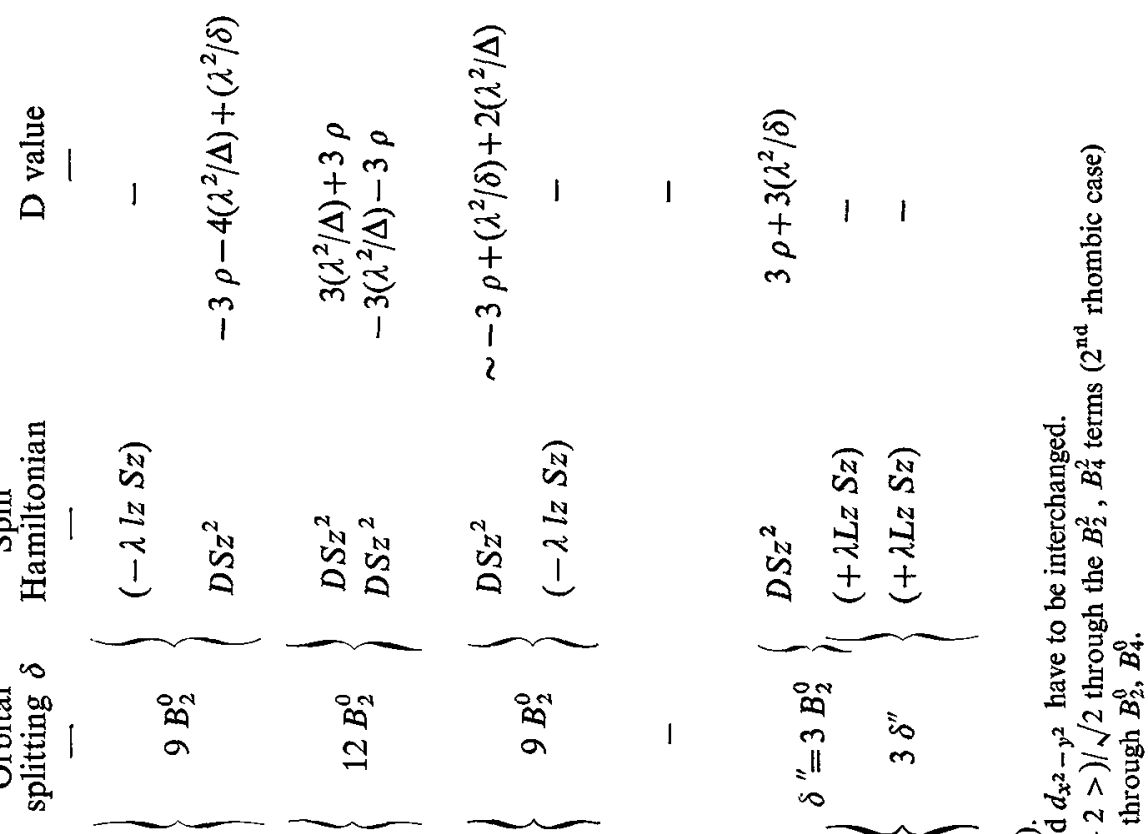

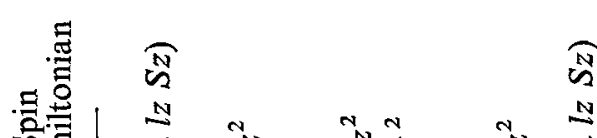

क蒙|

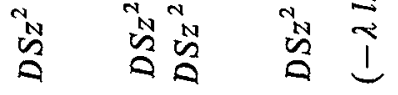
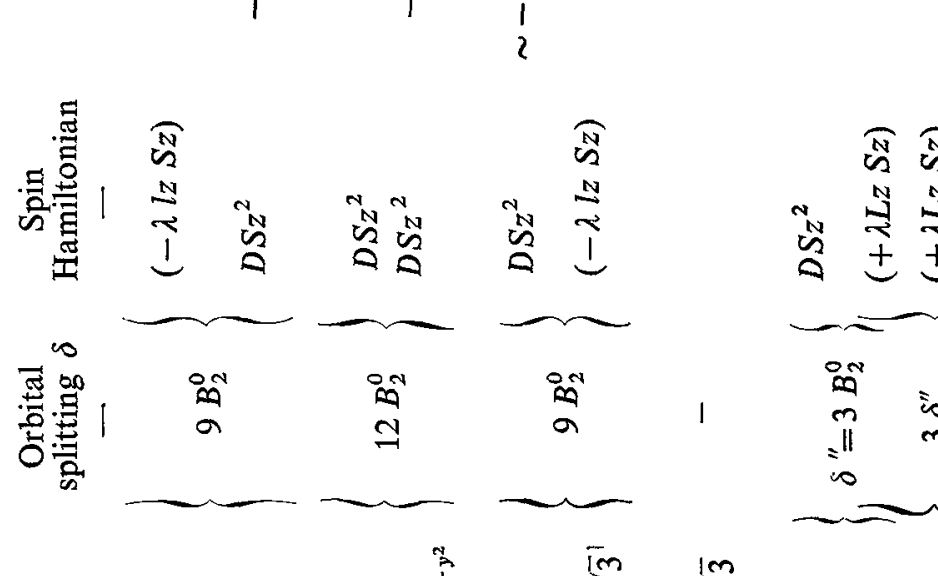

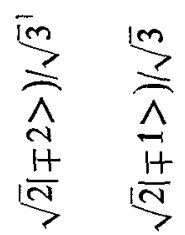
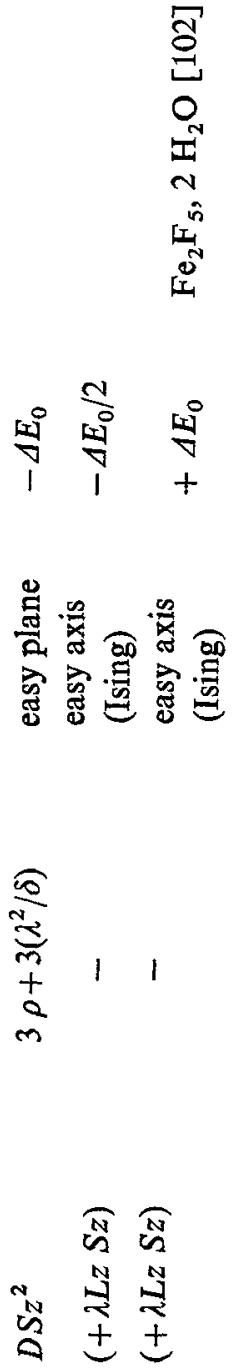
ed when the spin orbit coupling has no first order effect [15], i. e. in the case of orbital singlets. (Dropping the $\rho$-term leads to wrong level energies, but fairly correct wave functions.)

When the orbital splitting is large enough $(\delta \gg \lambda)$, a perturbation method [15-18] may be performed. An orbital singlet splits into five spin levels described by the spin Hamiltonian $D S z^{2}+E\left(S x^{2}-S y^{2}\right)$; an orbital doublet splits into five equally spaced doublets, as indicated on figure 3 (higher order perturbations splits two of these five doublets). The D values calculated for various cases are given in table I (it may be noticed that this 2 nd order perturbation calculation gives axial properties to the tetragonal and trigonal cases).
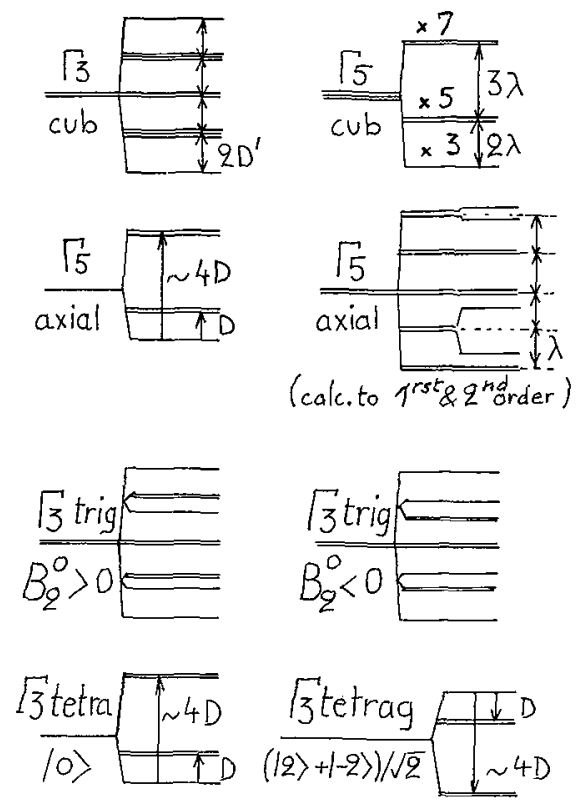

FIG. 3. - Spin levels in various cases. In the case labeled $\Gamma_{3} \mathrm{cub}, 2 D^{\prime}=6\left(\lambda^{2} / \Delta+\rho\right)[15]$.

2.1 Calculation WITHin $\Gamma_{5}$. - When the spin orbit coupling cannot be considered as a perturbation, the less complicated case is that of the $\Gamma_{5}$ ground state when the non cubic terms are weak enough to avoid the $\Gamma_{3}$ admixture. Within the $\Gamma_{5}$ manifold a fictitious orbital momentum $l=1$ can be defined, with components proportional to those of $\mathbf{L}$, according to the relation $\mathbf{l}=-\mathbf{L}$ (this relation has to be modified for powers of the components).

Rather than re-expressing the crystal field operators as functions of 1 , one may use equivalent operators in the $l=1$ multiplicity : only two of them have non null matrix elements, and the electronic Hamiltonian becomes (the $\rho$-term has been dropped for simplicity) :

$$
\begin{aligned}
& 3 \mathcal{C}^{\prime}\left(\Gamma_{5}\right)= \\
& =b_{2}^{0} O_{2}^{0}(\mathbf{I})+b_{2}^{2} O_{2}^{2}(\mathbf{l})-\lambda \mathbf{l} . \mathbf{S}+\mu_{\mathrm{B}} \mathbf{H} .(-\mathbf{I}+2 \mathbf{S}) \\
& =b_{2}^{0}\left[3 l z^{2}-l(l+1)\right]+\left(b_{2}^{2} / 2\right)\left[l^{+2}+l^{-2}\right]- \\
& \quad-\lambda \mathbf{l} . \mathbf{S}+\mu_{\mathrm{B}} \text { H. }(-\mathbf{I}+2 \mathbf{S}) .
\end{aligned}
$$

The $b_{2}^{0}$ and $b_{2}^{2}$ coefficients have been related to the coefficients $B_{n}^{m}$ by performing exact calculations in the ${ }^{5} \mathrm{D}$ term :

$$
b_{2}^{0} \sim+3 B_{2}^{0}-(80 / 3) B_{4}^{0}-(2 \sqrt{2} / 3) B_{4}^{3}
$$

(trigonal case)

$b_{2}^{0} \sim-3 B_{2}^{0}-20 B_{4}^{0}+4 B_{4}^{4}$

(tetragonal case)

$b_{2}^{2} \sim+4 B_{2}^{2}-6 B_{4}^{2}$

(rhombic case) .

(It may be noticed that the trigonal and tetragonal cases are represented by an axial Hamiltonian; $b_{2}^{2}$ is the splitting of the $l_{z}= \pm 1$ levels.)

To obtain the electronic level scheme of $\mathcal{H}^{\prime}\left(\Gamma_{5}\right)$, the diagonalization of a $15 \times 15$ matrix is then performed by computer. This has been done for various axial cases (NiO, $\mathrm{MnO}$ [19], $\mathrm{FeCl}_{2}$ [7], $\mathrm{FeSiF}_{6}$, $6 \mathrm{H}_{2} \mathrm{O}$ [8]). Systematic calculations for both axial and non-axial cases have been done by Ingalls [6]; this method is now very popular; its only disadvantage is that terms involving $\rho$ or $\lambda^{2} / \Delta_{\mathrm{cub}}$ are neglected in the calculation of the spin level splittings. Anyway, when $\Gamma_{3}$ is the ground state, or when the $\Gamma_{3}-\Gamma_{5}$ mixing occurs, a more complex method must be used.

2.2 General Calculation. - The exact resolution of $\mathcal{H}$ involves the diagonalization of a $25 \times 25$ matrix (dimension of the complete basis $=(2 L+1)$ $(2 S+1)=25)$. However, when $\mathbf{H}_{\mathrm{app}}$ is null or lies along the quantization axis, the $25 \times 25$ matrix reduces to several sub-matrices, whose elements in the standard basis have been tabulated in ref. [14b] for the trigonal, tetragonal and rhombic cases.

Now let us consider the hyperfine interactions :

For the usual assumption of fast electronic relaxation, they may be expressed as thermal averages of the following electronic operators:

$$
\begin{gathered}
V_{i j}(\mathrm{val})=(2 / 21)|e|\left\langle r_{Q}^{-3}>_{3 \mathrm{~d}}\{(3 / 2) \times\right. \\
\left.\times\left(L_{i} L_{j}+L_{j} L_{i}\right)-\delta_{i j} L(L+1)\right\} \\
\mathbf{H}_{\text {hyp }}=A \mathbf{S} \quad(\text { Fermi term })+ \\
+(1 / 21) \mu_{\mathrm{B}}\left\langle r_{D}^{-3}>_{3 \mathrm{~d}}\{L(L+1) \mathbf{S}-(3 / 2) \mathbf{L}(\mathbf{L} . \mathbf{S})-\right. \\
\quad-(3 / 2)(\mathbf{L} . \mathbf{S}) \mathbf{L}\} \quad \text { (dipolar term) } \\
-2 \mu_{\mathrm{B}}<r_{L}^{-3}>_{3 \mathrm{~d}} \mathbf{L} \quad \text { (orbital term) }
\end{gathered}
$$

where $\left\langle r_{Q, D, L}^{-3}\right\rangle_{3 \mathrm{~d}}$ have been each used so as to explicit different screening effects; practically they may be confused (this discussion is given in [80] and [89]).

Taking into account the lattice charges, the actual electric field gradient acting on the nucleus is :

$$
V_{i j}=V_{i j}(\mathrm{val})+\left(1-\gamma_{\infty}\right) V_{i j}(\mathrm{latt}),
$$

where $1-\gamma_{\infty} \simeq 10[20]$. 
Useful expression is that of the quadrupolar splitting; where $O X Y Z$ are principal axes of the EFG :

$$
\Delta E_{Q}=\left(|e| Q V_{z z} / 2\right) \sqrt{1+\eta^{2} / 3}
$$

(called quadrupolar interaction).

Since the calculations are worked out in a complete basis, the following property can be used : Let $M(O)$ and $M\left(O^{\prime}\right)$ be the matrices associated with the operators $O$ and $O^{\prime}$; then :

$$
M\left(O \times O^{\prime}\right)=M(O) \times M\left(O^{\prime}\right) .
$$

Consequently the calculations of $V_{i j}$ and $\mathbf{H}_{\mathrm{byp}}$ only require successive products of the elementary matrices associated with $L z, L^{+}, L^{-}, S z, S^{+}, S^{-}$, which are easy to obtain by computer (the $\lambda$ and $\rho$-terms calculated in ref. [14] have been checked in this way).

The hyperfine tensor formalism may help to calculate the hyperfine field. This formalism holds when the applied field or the molecular field does not mix the orbital levels. The hyperfine field in axial symmetry is expressed as :

$$
\mathbf{H}_{\text {hyp }}=U<\mathbf{S}_{\perp}>/ S+V<\mathbf{S}_{\|}>/ S
$$

( $\perp$ and $\|$ refer to the symmetry axis).

The following expressions for $U$ and $V$ have been deduced from the work of Okiji and Kanamori [4] :

$U=A S-4\left(g_{\perp}-2\right) \mu_{\mathrm{B}}\left\langle r^{-3}\right\rangle_{3 \mathrm{~d}}-\mu_{\mathrm{B}} V_{x x} /|e|$ $V=A S-4\left(g_{\mid l}-2\right) \mu_{\mathrm{B}}\left\langle r^{-3}\right\rangle_{3 \mathrm{~d}}-\mu_{\mathrm{B}} V_{z z}|| e \mid$.

(Similar expressions have been given by Marshall and Johnson [21]; $A$ is positive).

In the following we shall adopt the usual convention to assign a positive sign to $\mathbf{H}_{\text {hyp }}$ when it is antiparallel to the spin, i. e. parallel to the net magnetization. The free ion value of the Fermi term is $\sim-550 \mathrm{kOe}$ [20]. The anisotropic orbital term is positive when $\mathbf{S}$ lies in an easy direction, and may exceed the Fermi term in some cases as $\mathrm{FeCO}_{3}$ [79], $\mathrm{Fe}_{2} \mathrm{Mo}_{3} \mathrm{O}_{8}$ [14a]. The dipolar term is proportional to the E. F. G. and may amount up to $150 \mathrm{kOe}$.

3. The electric field gradient (E. F. G.). - The electronic level scheme strongly influences the Mössbauer spectra through the hyperfine interactions as well as through the magnetic anisotropy. The magnetic-anisotropy effects have been discussed in ref. [15, 18] and are summarized in table I. Here we discuss in more detail the quadrupole interaction.

3.1 The paramagnetic Case. - A frequent situation is that of a well isolated orbital ground state $(\lambda \ll \delta)$ belonging to the $\Gamma_{5}$ manifold, in axial symmetry. The principal component $V_{z z}$ (val), according to previous calculations [2-5] may present one of the following two values (in absolute value) :

$$
\left|\begin{array}{ll}
V_{z z}(\mathrm{val}) \\
V_{z z}(\mathrm{val})
\end{array}\right|=V_{0} \quad \text { (orbital singlet) }
$$

where $V_{0}=(4 / 7)|e|\left\langle r_{Q}^{-3}\right\rangle_{3 d}$ leads to a quadrupole interaction $\Delta E_{0}$ amounting $5 \mathrm{~mm} / \mathrm{s}$ in the more ionic hosts $[6,20]$, and sizeably reduced in covalent hosts. The signs of $V_{z z}$ in various cases are listed in table I.

In the case of non axial symmetry, Ganiel [24] has shown that any isolated orbital singlet of the $\Gamma_{5}$ or $\Gamma_{3}$ manifolds produces a quadrupole interaction equal to $\Delta E_{0}$; this result has been shown by Zimmermann and Spiering [25] to hold when the spin-orbit coupling is included in the $\Gamma_{5}$ levels (with $\lambda \ll \delta$ ). Systematic calculations of $V_{z z}$ and $\eta$ as functions of the orbital wave functions have been carried out [43]. The present calculations show that Ganiel's rule does not apply in the case of a $\Gamma_{5}-\Gamma_{3}$ mixing.

The spin-orbit coupling and temperature effects reduce the calculated E. F. G. [6] (in absolute value). Therefore $\Delta E_{0}$ is the actual maximum value for the quadrupole interaction of intra-atomic origin, and is often used to fit the data instead of $Q\left\langle r_{Q}^{-3}\right\rangle_{3 \dot{d}}$.

Now let us systematically describe the behaviour of $\Delta E_{Q}$ (val) in the crystal field approach. This behaviour depends on the sign of the cubic field. Octahedral ( $\Gamma_{5}$ ground state) and tetrahedral $\left(\Gamma_{3}\right.$ ground state) sites will be considered separately.

3.1.1 Octahedral case (ground $\Gamma_{5}$ ). - We use the Ingalls' description [6] which holds fairly well in most cases. The calculated E. F. G. depends only on the orbital splittings and on temperature - expressed in units of $\lambda$ :

$$
\begin{aligned}
& V_{z z}(\mathrm{val})=V_{0} F\left(\delta_{1} / \lambda, \delta_{2} / \lambda, T / \lambda\right) ; \\
& \eta V_{z z}(\mathrm{val})=V_{0} f\left(\delta_{1} / \lambda, \delta_{2} / \lambda, T / \lambda\right)
\end{aligned}
$$

where $F<1$. The final expression for $\Delta E_{Q}$, including both the $3 \mathrm{~d}$ and lattice contributions is rather complicated in the non-axial case, but simple in the axial case, as follows :

$$
\Delta E_{Q}=\Delta E_{0} F(\delta / \lambda, T / \lambda)+\Delta E_{Q} \text { (latt) } .
$$

The thermal variation of $\Delta E_{Q}$, drawn on figure 4 , results from the thermal population of different levels :

(i) spin levels of the spin hamiltonian, giving a sharp variation in the temperature range $0-50 \mathrm{~K}$;

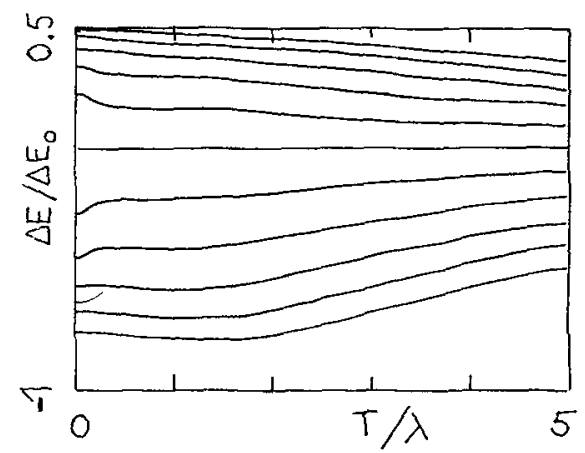

FrG. 4. - Thermal dependence of $\Delta E_{Q}$ (val) in octahedral site of axial symmetry, $\delta / \lambda= \pm 1,2,3,4,5$. 
(ii) excited levels associated with excited orbital levels, giving a smooth variation at higher temperatures.

Therefore the thermal dependence of $\Delta E_{Q}$ enables, in principle, $\delta$ and $\lambda$ to be determined, as far as the sign of $\Delta E_{Q}$ is known. In practice, for small $\delta(<3 \lambda)$, only the ratio $\delta / \lambda$ (the so-called Figgis parameter) can be accurately determined [26] (the same holds for EPR measurements [27]). While for large $\delta(>8 \lambda)$ only $\delta$ can be accurately determined (See for instance [28]).

In the case of a low symmetry, the knowledge of both $V_{z z}(T)$ and $\eta(T)$ is needed to obtain a reasonable assessment of the orbital splittings $\delta_{1}$ and $\delta_{2}$ [29]; $\eta$ can be easily measured when the system orders magnetically. In paramagnets $\eta$ can be measured by various methods :

(i) line intensity measurements in a single crystal [30],

(ii) single crystal in a magnetic field [31],

(iii) field-aligned powdered sample [32],

(iv) powder in an applied field.

For this last method, the well known description [33] has to be modified to take into account the anisotropic hyperfine field due to the ion magnetization [34].

As a final remark, it was shown by Zimmermann and Spiering [25] that Ingalls' method developed for the rhombic case actually applies to any case of low symmetry (as far as the $\Gamma_{3}$ admixture may be neglected).

3.1.2 Tetrahedral site (ground $\Gamma_{3}$ ). - In a trigonal crystal field, $\Gamma_{3}$ remains orbitally degenerate and complications may occur from dynamical JahnTeller effect [23] (this situation is encountered in $\mathrm{ZnS}$ Wurtzite [35]).

Although the orbital degeneracy of $\Gamma_{3}$ is not lifted, an E. F. G. is produced by the $\Gamma_{5}$ admixture. This gradient depends little on temperature as soon as the spin levels are equally populated (Fig. 5).

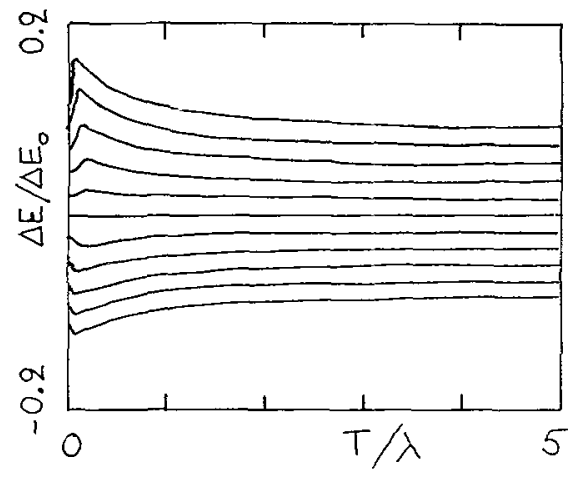

Fig. 5. - Thermal dependence of $\Delta E_{Q}$ (val) in tetrahedral site of trigonal symmetry, $\delta\left(\Gamma_{5}\right) / \lambda= \pm 1,2,3,4,5$.

In a tetragonal crystal field, the orbital degeneracy is removed. In the case of a well isolated ground state, the maximum quadrupole interaction is obtained (see Table I). Spin-orbit coupling has little influence on the E. F. G. and the temperature dependence of $\Delta E_{Q}$ may be expressed as a Tanh-law with a good accuracy (Fig. 6).

3.1.3 Purely axial site. - In some cases, the cubic field may be negligible; this situation might occur when the iron coordination differs from $4,6,8$. The orbital wave functions are then very simple and yield

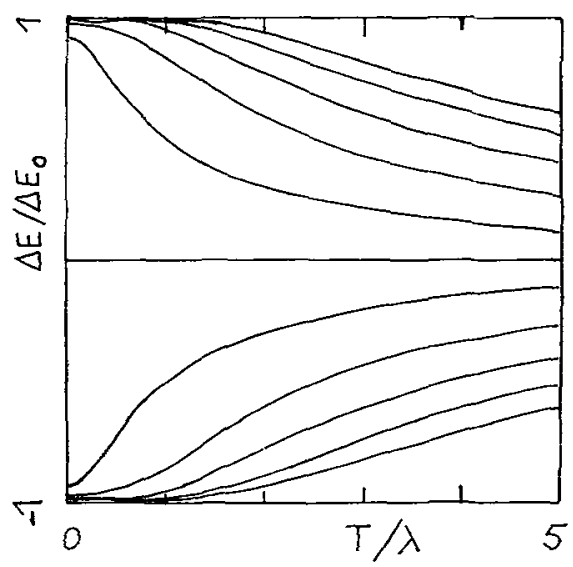

Fig. 6. - Thermal dependence of $\Delta E_{Q}$ (val) in tetrahedral site of tetragonal symmetry, $\delta^{\prime} / \lambda= \pm 1,2,3,4,5$.

the following quadrupole values: $\pm \Delta E_{0},-\Delta E_{0} / 2$ (see Table I).

When the spin-orbit coupling and temperature effects are taken into account, a reduction of the E. F. G. is observed, illustrated on figure 7.

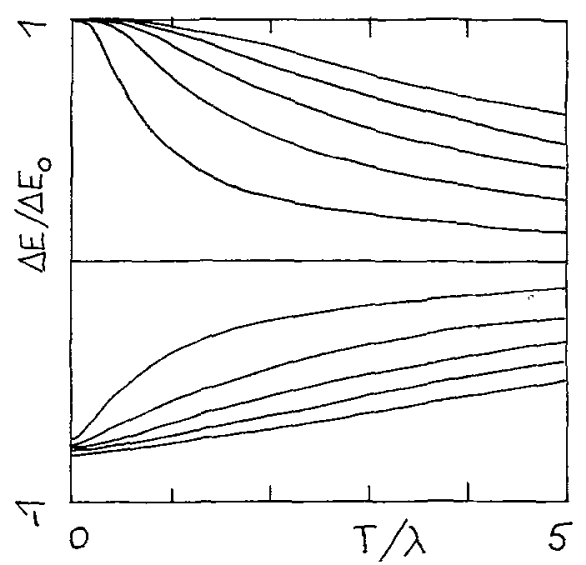

FIG. 7. - Thermal dependence of $\Delta E_{Q}$ (val) in purely axial site, $\delta^{\prime \prime} / \lambda= \pm 1,2,3,4,5$.

3.2 The magnetically induced E. F. G. - An applied magnetic field influences the E.F. G. [36] because the additional term $+\mu_{\mathrm{B}} \mathbf{H}_{\mathrm{app}} \cdot(\mathbf{L}+2 \mathbf{S})$ in the Hamiltonian modifies the wave functions; a molecular field produces a similar effect [7]. In the $\Gamma_{5}$ manifold, systematic calculations concerning the principal component have been performed in cubic [36c] and non cubic [37] sites. 


\section{TABLE II}

Sign of the induced electric field gradient : $V_{z z}$ and $\eta$, for particular orientations of $H_{\mathrm{app}}$

\begin{tabular}{|c|c|c|c|c|c|c|}
\hline Symmetry & Site & $\begin{array}{c}\text { Orbital } \\
\text { ground state }\end{array}$ & $\begin{array}{l}\text { Sign of the } \\
\text { principal } \\
\text { component }\end{array}$ & $\underset{\text { direction }}{\mathrm{H}_{\mathrm{app}}}$ & $\begin{array}{l}\text { Induced } \\
\text { principal } \\
\text { component }\end{array}$ & $=\stackrel{\left(V_{H_{\mathrm{app}}}-V_{\perp}\right) / V_{z 2}}{\quad \text { Induced }}$ \\
\hline Tetragonal & Octa & $\begin{array}{l}\text { doublet } \\
\text { singlet } \\
\text { (singlet) } \\
\text { (singlet) }\end{array}$ & $\begin{array}{l}- \\
+ \\
+\end{array}$ & $O z, O x, O u$ & $\begin{array}{c}-,+,+ \\
+,-,- \\
\sim 0(+,-,-) \\
\sim 0(+,-,-)\end{array}$ & $\begin{array}{l}0,+, \sim 0 \\
0,-, \sim 0 \\
0,-, \sim 0 \\
0,+, \sim 0\end{array}$ \\
\hline Trigonal & $\begin{array}{l}\text { Octa } \\
\text { Tetra }\end{array}$ & $\begin{array}{l}\text { doublet } \\
\text { singlet } \\
\text { doublet }\end{array}$ & $\begin{array}{l}+ \\
- \\
- \\
+\end{array}$ & $O z, O x, O y$ & $\begin{array}{l}+,-,- \\
-,+,+ \\
-,+,+ \\
-,+,+\end{array}$ & $\begin{array}{l}0,+,+ \\
0,-,- \\
0,-,- \\
0,+,+\end{array}$ \\
\hline Cubic & $\begin{array}{l}\text { Octa } \\
\text { Tetra }\end{array}$ & $\begin{array}{l}\text { triplet } \\
\text { doublet }\end{array}$ & 0 & $<100>$ & $\begin{array}{l}-,+ \\
+, \sim 0(-)\end{array}$ & $\begin{array}{l}0,0 \\
0,0\end{array}$ \\
\hline purely axial & & $\begin{array}{c}\text { singlet } \\
\text { doublet } \mid \pm 2>\end{array}$ & $\bar{t}$ & $O z, O x$ & $\begin{array}{l}-,+ \\
+,-\end{array}$ & $\begin{array}{l}0,- \\
0, \sim 0(+)\end{array}$ \\
\hline
\end{tabular}

$O x y z$ are defined according to figure 1 ; Ou bissects $O x, O y$.

For all these orientations of $H_{\mathrm{app}}$, note that $O z$ and $H_{\mathrm{app}}$ are principal axes of the EFG; this is not true for an arbitrary orientation of $H_{\text {app. }}$.

Note also that induced and non-induced $V_{z z}$ have the same sign for $H_{\text {app }}$ parallel to $O z$, opposite signs for $H_{\text {app }}$ perpendicular to $O_{z}$ (excepted for the case of trigonal $\Gamma_{3}$ for which Jahn-Teller effects are to be expected).

Large induced effects are expected when an important reduction due to the spin-orbit coupling is present (then Ganiel's rule does not apply and the hyperfine tensor formalism does not hold). In such cases, by measuring the induced effects, a determination of the spin-orbit coupling constant is in principle possible. Expressions for the anisotropic induced E. F. G., suited to the case of $\mathrm{FeCr}_{2} \mathrm{O}_{4}$, are given in [18] (3rd order perturbations yield the result that induced value of $\eta$ strongly depends on the orientation of Happ in the basal plane, and that generally the gradient axes do not coincide with the spin direction).

We have calculated (Table II) the sign of the induced gradient in several cases of axial symmetry; this sign depends on the direction of the applied field. It is worth recalling that these induced effects are greatly disturbed when dynamical Jahn-Teller effects are present [38].

3.3 REMARK CONCERNING THE LATTICE CONTRIBUTION to tHE E. F. G. - Since $V_{z z}$ (latt) and $\eta V_{z z}$ (latt) appear in the expression for the actual quadrupole interaction, it would be very convenient to obtain a confident estimate of these contributions. The magnitude of $\Delta E_{Q}$ (lattice), according to $\mathrm{Fe}^{3+}$ data, is expected ro range from 0 to $\sim 0.8 \mathrm{~mm} / \mathrm{s}$ in most compounds, where $\mathrm{Fe}^{2+}$ has octahedral or tetrahedral environment, although it was observed to be larger in planar systems, $\sim 1.4 \mathrm{~mm} / \mathrm{s}$ in $\mathrm{MFeF}_{4}$ [39]. With other coordinations the lattice term might be even larger, reaching $2.3 \mathrm{~mm} / \mathrm{s}$ in $\mathrm{BaFe}_{12} \mathrm{O}_{19}$ [115] where $\mathrm{Fe}^{3+}$ is five-fold coordinated.

A method was proposed by Ingalls [6], who pointed out that both $V_{z z}$ (latt) and $B_{2}^{0}$ (2nd order axial crystalline potential) were proportional to the summation

$$
\sum_{i} Z_{i}\left(3 z_{i}^{2}-r_{i}^{2}\right) / r_{i}^{5},
$$

while both $\eta V_{z z}$ (latt) and $B_{2}^{2}$ (2nd order non-axial crystal line potential) were proportional to

$$
\sum_{i} Z_{i}\left(x_{i}^{2}-y_{i}^{2}\right) / r_{i}^{5} .
$$

The main obstacle against this method is that the proportionality factor for the crystalline potential is likely to greatly depend on the host. Therefore this method would apply for comparing $\mathrm{Fe}^{2+}$ in very similar hosts : for instance, the same first coordination shell in a series of isostructural compounds...

Anyway, the very safe method, which requires the accurate knowledge of the crystallographic structure, consists in performing point-charge and dipole summations over the lattice [40] (by the way it is worth indicating that computer time is saved by carrying out the summation over Wigner-Seitz cells).

3.4 THE HYPERFINE FIELD $\left(H_{\text {hyp }}\right)$. - Accurate previsions concerning the hyperfine field are difficult to obtain, because of the large uncertainties concerning the values of $A$ and $\left\langle r^{-3} L, D\right\rangle$. In addition, other contributions to the internal field experienced by the 
TABLE III

Crystal field studies accounting for both quadrupolar and magnetic data

\begin{tabular}{|c|c|c|c|c|c|}
\hline Host & $\begin{array}{l}\text { Ground and } \\
\text { Symmetry }\end{array}$ & $\begin{array}{c}\Delta E_{Q}, \eta(0 \mathrm{~K}) \\
\mathrm{mm} / \mathrm{s}\end{array}$ & $\begin{array}{l}\text { Easy } \\
\text { magn. }\end{array}$ & $\begin{array}{l}\text { mol (and appl.) } \\
\text { field }\end{array}$ & $\begin{array}{c}\mathrm{Hi}(\mathrm{O} \mathrm{K}) \\
\mathrm{kOe}\end{array}$ \\
\hline $\mathrm{FeF}_{2}$ & $\Gamma_{5}$, rhomb & $+2.85,0.40$ & & $O_{z}$ & $(-329$ \\
\hline $\mathrm{FeV}_{2} \mathrm{O}_{4}$ & $\Gamma_{3}, \sim$ tetrag & $+3.15, \sim 0$ & $o_{z}$ & $O z$ & $(-) 86$ \\
\hline $\mathrm{FeCr}_{2} \mathrm{O}_{4}$ & & $-3.05, \sim 0.2$ & $x O y$ & $O x, x O y$ & $(-150,180$ \\
\hline $\mathrm{Zn} / \mathrm{MgCr}_{2} \mathrm{O}_{4}$ & $\Gamma_{3}$, tetrag & $+3.1,0$ & $O_{z}$ & $O z$ & $(-) 130$ \\
\hline$(\mathrm{Ni}, \mathrm{Fe}) \mathrm{Cr}_{2} \mathrm{O}_{4}$ & & $+3.2, \sim 0$ & $O z$ & $O x$ & (- 439 \\
\hline $\mathrm{GeFe}_{2} \mathrm{O}_{4}$ & & $-2.9,0$ & $x O y$ & $O x$ & $(-) 163$ \\
\hline $\mathrm{GeCO}_{2} \mathrm{O}_{4}$ & $\Gamma_{5}$, trig & $-2.9,0$ & $x O y$ & oblique & $(-260$ \\
\hline $\mathrm{GeNi}_{2} \mathrm{O}_{4}$ & & $-3.1,0$ & $x O y$ & oblique & $(-) 302$ \\
\hline $\begin{array}{l}\mathrm{CdCr}_{2} \mathrm{~S}_{4} \\
\mathrm{COCr}_{3} \mathrm{~S}_{4}\end{array}$ & $\Gamma_{3}$ cub, tetrag & $\begin{array}{l}+2.87,0 \\
+2720\end{array}$ & $\begin{array}{l}001 \\
001\end{array}$ & 001 & 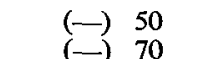 \\
\hline $\mathrm{CoCr}_{2} \mathrm{~S}_{4}$ & $\Gamma_{3}$ cub & $+1.20,0(10 \mathrm{~K})$ & 001 & 001 & (-) 192 \\
\hline $\mathrm{FeCr}_{2} \mathrm{~S}_{4}$ & $\Gamma_{3}$ tetrag & $-2.7, \sim 0$ & $x O y$ & $x O y$ & (-) 198 \\
\hline $\begin{array}{l}\mathrm{Fe}_{1.06} \mathrm{Cr}_{1.94} \mathrm{~S}_{4} \\
\mathrm{ZnS} \\
\mathrm{Fe} / \mathrm{MgAl}_{2} \mathrm{O}_{4}\end{array}$ & $\begin{array}{l}\Gamma_{3} \text { tetrag } \\
\Gamma_{3} \sim \text { tetrag } \\
\Gamma_{3} \text { (tetrag?) }\end{array}$ & $\begin{aligned} & 0.97(300 \mathrm{~K}) \\
+ & 3.2, \sim 0\end{aligned}$ & & & \\
\hline $\mathrm{FeCl}_{2}$ & $\Gamma_{5}$, trig & $\begin{array}{c}+1.2,0 \\
\quad \text { increased } \\
\text { decreased }\end{array}$ & $O z$ & $\begin{array}{c}O_{z} \\
O z(\text { and } O z) \\
O z\end{array}$ & $\begin{array}{l}+4 \\
+3\end{array}$ \\
\hline $\mathrm{CoCl}_{2}$ & $\Gamma_{5}$, trig & +1 & $O z$ & $\underset{O x}{O z}$ & $\sim 60$ \\
\hline $\mathrm{NiCl}_{2}$ & $\Gamma_{5}$, trig & +1.65 & $o_{z}$ & $O_{z}$ & $\sim 35$ \\
\hline $\begin{array}{l}\mathrm{MgCl}_{2} \\
\mathrm{FeBr}_{2}\end{array}$ & $\begin{array}{l}\Gamma_{5}, \text { trig } \\
\Gamma_{5}, \text { trig }\end{array}$ & $\begin{array}{l}+1 ., 0 \\
+1.13,0\end{array}$ & $\begin{array}{l}O z \\
O z\end{array}$ & $O z$ & +30 \\
\hline $\mathrm{FeI}_{2}$ & $\Gamma_{S}$, trig & $+0.96,0$ & $O z$ & $O z$ & +74 \\
\hline $\begin{array}{l}\mathrm{FeCl}_{2}, 2 \mathrm{H}_{2} \mathrm{O} \\
\mathrm{FeCl}_{2}, 4 \mathrm{H}_{2} \mathrm{O}\end{array}$ & $\begin{array}{l}\Gamma_{\mathrm{s}}, \text { rhomb } \\
\Gamma_{\mathrm{s}} \text {, rhomb }\end{array}$ & $\begin{array}{r}+2.50,0.3 \\
+3.10,0.2\end{array}$ & & $\begin{array}{c}O x \\
\text { oblique }\end{array}$ & $\begin{array}{l}(-)^{2} 251 \\
(-) 266\end{array}$ \\
\hline $\begin{array}{l}\mathrm{Fe}(\mathrm{py})_{2} \mathrm{Cl}_{2} \\
\mathrm{FeCO}_{3} \\
\mathrm{MnCO}_{3}\end{array}$ & $\begin{array}{l}\Gamma_{5}, \sim \text { tetrag } \\
\Gamma_{5}, \text { trig } \\
\Gamma_{5}, \text { trig }\end{array}$ & $\begin{array}{l}+1.2, \sim 0 \\
+2.06,0 \\
+1.06,0.1\end{array}$ & $\begin{array}{l}O z \\
O z\end{array}$ & $\stackrel{O z}{\sim O x}$ & $\begin{array}{l}+184 \\
(+) 195\end{array}$ \\
\hline $\mathrm{CoCO}_{3}$ & $\Gamma_{5}$, trig & $+1.95,0.2$ & $O z$ & $O x$ & 72 \\
\hline $\mathrm{FeZnMo}_{3} \mathrm{O}_{8}$ & $\Gamma_{3}$, trig & $+1.30,0$ & $O_{z}$ & $O z$ & +111 \\
\hline $\mathrm{Fe}_{2} \mathrm{Mo}_{3} \mathrm{O}_{8}$ & $\begin{array}{l}\Gamma_{3}, \text { trig } \\
\Gamma_{5} \text { trig }\end{array}$ & $\begin{array}{l}+0.97,0 \\
+1.63,0\end{array}$ & $\begin{array}{l}O z \\
O z\end{array}$ & $\begin{array}{l}O z \\
O z\end{array}$ & $\begin{array}{l}(+) 58 \\
(+) 183\end{array}$ \\
\hline $\mathrm{MTiO}_{3}$ & $\Gamma_{5}$, trig & +0.4 to 1.6 & $O z$ & various & -34 to -105 \\
\hline $\begin{array}{l}\mathrm{MnTiO}_{3}-\mathrm{II} \\
\mathrm{FeSiF}_{6}, 6 \mathrm{H}_{2} \mathrm{O}\end{array}$ & $\begin{array}{l}\Gamma_{5}, \text { trig } \\
\Gamma_{5}, \text { trig }\end{array}$ & $\begin{array}{l}-1.9 \\
-3.60\end{array}$ & $o x$ & $O x$ & $\leftrightarrow 85$ \\
\hline & $\Gamma_{5}$, rhomb & $\begin{array}{l}-3.60 \\
-360.32\end{array}$ & $O y$ & various & \\
\hline $\begin{array}{l}\mathrm{ZnSiF}_{6}, 6 \mathrm{H}_{2} \mathrm{O} \\
\mathrm{Fe}\left(\mathrm{ClO}_{4}\right)_{2}{ }_{6} \mathrm{H}_{2} \mathrm{O}\end{array}$ & $\begin{array}{l}\Gamma_{5}, \text { trig } \\
\Gamma_{5} \text { rhomb }\end{array}$ & $\begin{array}{l}-3.60,0.32 \\
=2.1,0 \\
=3.48, ?\end{array}$ & $\begin{array}{c}x O y \\
O y\end{array}$ & $H_{\mathrm{app}}$ & \\
\hline $\begin{array}{l}\mathrm{KFeF}_{3} \\
\mathrm{MnO} / \mathrm{NiO}\end{array}$ & $\begin{array}{l}\Gamma_{5}, \text { trig } \\
\Gamma_{5}, \text { cub }\end{array}$ & $\begin{array}{l}-3.48, \\
+0.80(37 \mathrm{~K}), 0 \\
1.8, \sim 1 / 1.0, \sim 1\end{array}$ & $O y$ & $\begin{array}{l}o_{z}=<111>> \\
<112>?\end{array}$ & $\begin{array}{l}(-) 155(37 \mathrm{~K}) \\
(-) 97 /(-) 55\end{array}$ \\
\hline $\mathrm{KFeCl}_{3}$ & $\Gamma_{5}$, rhomb & $\begin{array}{l}+2.60,0.41 \\
+1 .\end{array}$ & & $\begin{array}{l}O x \\
O x\end{array}$ & $\leftrightarrow 168$ \\
\hline $\mathrm{RbFeBr}_{3}$ & $\begin{array}{l}\Gamma_{5}, \text { trig } \\
\Gamma_{5}, \text { trig }\end{array}$ & $\begin{array}{l}-1.8 \\
-1.7\end{array}$ & $\begin{array}{l}x O y \\
x O y\end{array}$ & $\begin{array}{l}O x \\
O x\end{array}$ & \\
\hline $\mathrm{Cu}_{2} \mathrm{GeFeS}_{4}$ & $\Gamma_{3}$, tetrag & $-2.53, \sim 0$ & $x O y$ & $O x$ & $(-) 167$ \\
\hline $\mathrm{Cu}_{2} \mathrm{SnFeS}_{4}$ & $\Gamma_{3}$, tetrag & $-2.92, \sim 0$ & $x O y$ & $o x$ & (-) 205 \\
\hline
\end{tabular}

nucleus, arising from dipolar fields and supertransferred fields, may be difficult to be estimated (they amount a few $10^{4} \mathrm{Oe}$ ). Nevertheless hyperfine field data must not be disregarded in crystal-field analyses.

A general remark is that in all cases the observed internal field is smaller than the Fermi term. This is due to the orbital term, which is large and positive when the spin lies in an easy direction. To observe a hyperfine field larger than the Fermi term would require saturating the spin in a hard direction. This unusual situation might be obtained with a ferrous ion strongly coupled with its magnetic neighbours [41]; this seemed to be the case of $\mathrm{NiCr}_{2} \mathrm{O}_{4}: \mathrm{Fe}^{2+}$ [107].

Induced effects are expected on the hyperfine field also. A magnetic field applied along the symmetry axis changes the saturation value of $H_{\text {hyp }}$ : this was observed in spin-flopped $\mathrm{FeCl}_{2}(\S 4.1)$. When the external (or molecular field) acts in the basal plane, a basal anisotropy appears; it has been evaluated in the case of $\mathrm{FeCr}_{2} \mathrm{O}_{4}$ [18]. 
The signs between parentheses are expected, not proved. Underlined values had been fixed.

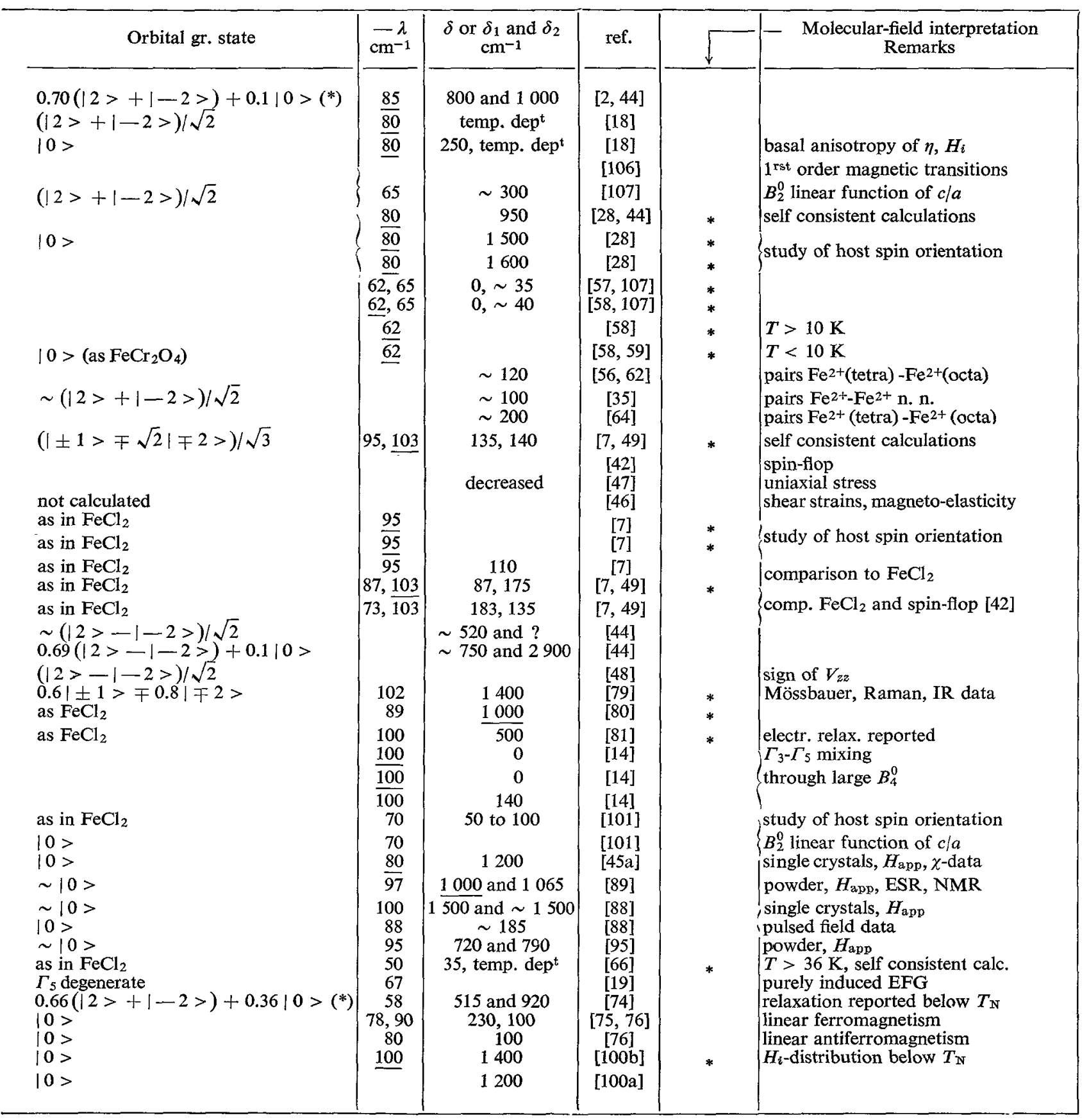

$\left(^{*}\right)=2-$ fold cubic axes basis.

Some complication would arise in the case of a dynamical Jahn-Teller effect, described in ref. [38].

\subsection{CRYSTAL-FIELD DETERMINATION PROCEDURE. -} In the light of the present calculations, it appears that the crystal field acting on $\mathrm{Fe}^{2+}$ determines the following quantities :

(i) $V_{z z}(T)$ in sign and magnitude.

(ii) $\eta(T)$.

(iii) The easy direction of the spin. (iv) $\mathbf{H}_{\text {hyp }}(0 \mathrm{~K})$ via the exchange term in $\mathscr{H}$.

(v) $\mathbf{H}_{\mathrm{kyp}}(T)$.

(vi) Magnetically induced effects on $V_{z z}, \eta, \mathbf{H}_{\text {hyp }}$.

Experimental data concerning all of these quantities are desirable, as well as the knowledge of the point symmetry. A convenient method is to determine first the orbital wave function of the ground state by taking into account both the point symmetry, the sign of the E. F. G. and the orientation of the internal field which 
is likely to be an easy direction, as is found in many compounds $[15,18]$. In the case of a paramagnet, similar information is obtained from single crystals when a magnetic field is applied along several directions. The crystal field level scheme may then be qualitatively deduced, and finally fitted to the data.

In addition, data from other studies (magnetic, spectroscopic...) are also desirable. The cases of $\mathrm{FeCO}_{3}$ and $\mathrm{FeSiF}_{6}, 6 \mathrm{H}_{2} \mathrm{O}$ illustrate this point.

4. Review of Mössbauer investigations. - A general feature of crystal-field studies by the Mössbauer effect is that the properties of the host lattice should be known first (conflicting literature in most cases originated from an incomplete knowledge of the lattice properties). Afterwards the properties of the ferrous ion can be determined and described in terms of crystal-field effects. These are the reasons why the crystal-field investigations reported in the present review mainly deal with the host lattice properties.

Earlier crystal-field studies have been reported in Greenwood and Gibb's book [44]. Those concerning $\mathrm{FeSb}_{2} \mathrm{O}_{4}, \mathrm{FeNb}_{2} \mathrm{O}_{6}, \mathrm{FeIn}_{2} \mathrm{~S}_{4}, \mathrm{Cu}_{2} \mathrm{FeSnS}_{4}$, Tutton salts, frozen solutions, were based on the temperature dependence of $\Delta E_{Q}$ alone, and should be regarded as incomplete. More complete information including the sign of $V_{z z}$ and the value of $\eta$ were used in the study of $\mathrm{FeSO}_{4}, 7 \mathrm{H}_{2} \mathrm{O}, \mathrm{Fe}\left(\mathrm{NH}_{4} \mathrm{SO}_{4}\right) 6 \mathrm{H}_{2} \mathrm{O}$ (together with magnetic susceptibility data) and other complexes containing $\mathrm{FeCl}_{4}^{2-}$. Crystal field studies accounting for both paramagnetic and magnetic spectra have been worked out for the following systems: $\mathrm{FeF}_{2}$, the spinels $\mathrm{FeV}_{2} \mathrm{O}_{4}$ [18], $\mathrm{FeCr}_{2} \mathrm{O}_{4}$ [18], $\mathrm{GeFe}_{2} \mathrm{O}_{4}$ [18], $\mathrm{FeCr}_{2} \mathrm{~S}_{4}$ [36] the metamagnetic systems $\mathrm{FeCl}_{2}$ [7], $\mathrm{FeBr}_{2}$ [7], $\mathrm{FeI}_{2}$ [7], $\mathrm{FeCO}_{3}$ (including spin-flopped phases), $\mathrm{FeCl}_{2}, 2 \mathrm{H}_{2} \mathrm{O}$ and $4 \mathrm{H}_{2} \mathrm{O}, \mathrm{MnO}$ and $\mathrm{NiO}$ [19] (for which the E. F. G. is mainly of induced origin), $\mathrm{RbFeF}_{3}$ and $\mathrm{KFeF}_{3}$. The paramagnet $\mathrm{FeSiF}_{6}$, $6 \mathrm{H}_{2} \mathrm{O}[45 a]$ has been studied by applying magnetic fields to single crystals. Essential results of these studies are given in table III.

We do not describe in greater detail these early studies, and now review more recent studies whose results are also given in table III.

4.1 $\mathrm{FeCl}_{2}$ AND Derivatives. - Since the initial work of Ono-Ito-Fujita [7] $\mathrm{FeCl}_{2}$ has been a source of great interest because of its metamagnetic and magnetoelastic properties. By flopping the spins, Simkin [42] measured the interionic dipolar contribution to $H_{i}$ in agreement with lattice sum expectations, and deduced the value of $H_{i}$ in zero external field: $+2.8 \mathrm{kOe}$. According to Simkin's data on the flopped phase, $H_{i}$ increases as a function of Happ ; this increase might be interpreted as field induced. We recently measured $H_{i}$ in applied fields up to $50 \mathrm{koe}$, and obtained an increase in $H_{i}$ equal to $0.13 \pm 0.02 \mathrm{kOe} / \mathrm{kOe}$, in agreement with Simkin's measurements; by using the crystal field model given in $\S 2.2$ and Ono-Ito's values, we calculated an expectation value of $0.23 \mathrm{kOe} / \mathrm{kOe}$, which is rather satisfactory (the difference might be due to magneto-elastic effects which have not been estimated at the present time).

Magnetic measurements by Carrara and Nasser [50] were very well accounted for by using Ono-Ito's values, rather than those of Hazony [49b].

Magnetic [51] and Mössbauer [47] measurements under uniaxial stress were used to determine the dependence of the axial splitting, $\delta$, as a function of stress : $\mathrm{d} \delta / \mathrm{d} p=-6 \pm 1 \mathrm{~cm}^{-1} / \mathrm{kbar}$ at low temperature was obtained. It was also shown that the variations of $V_{z z}$ (val) and $V_{z z}$ (latt) just cancel each other at room temperature. Since the Mössbauer-under-stress device could not work at $4.2 \mathrm{~K}$, the stress dependence of $H_{i}$ remains unknown. Figure 8 summarizes this study.
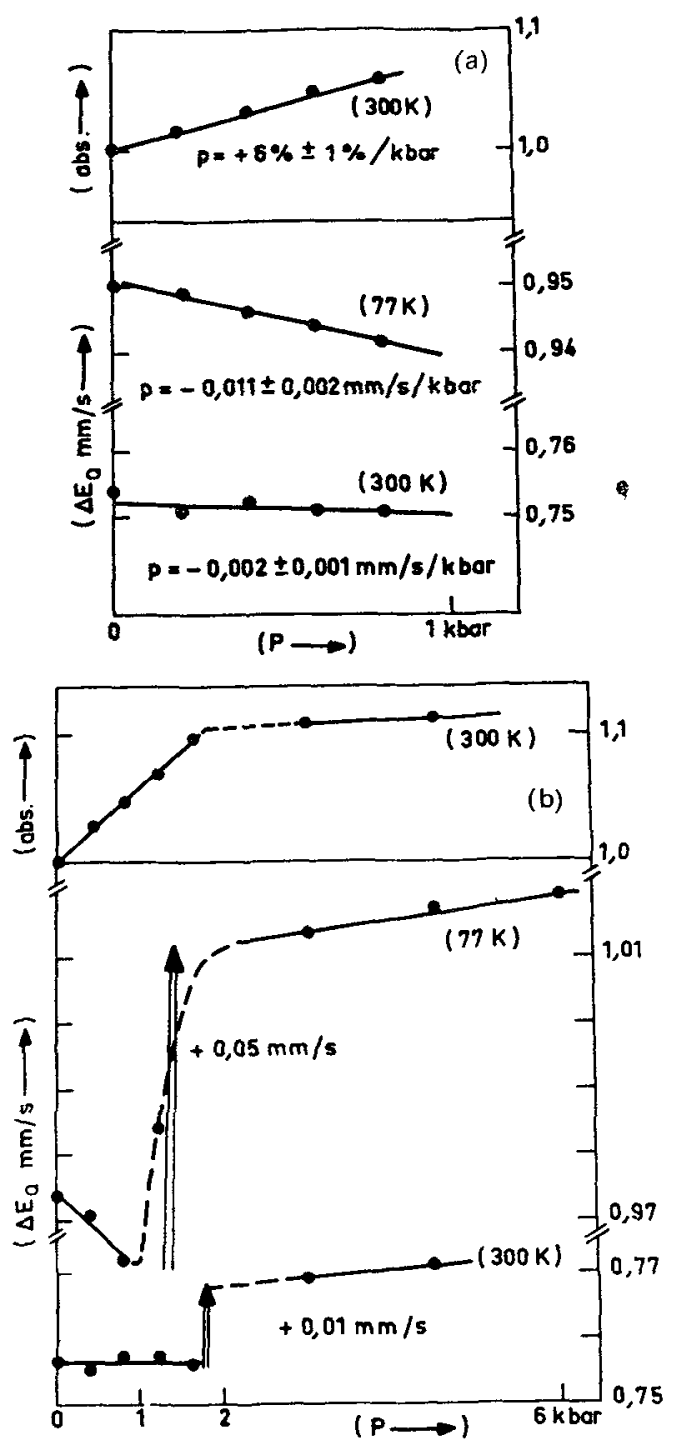

Fig. 8. - $\mathrm{FeCl}_{2}$ single crystal submitted to a [001] uniaxial stress [47]. A phase transition occurs between 1 and $2 \mathrm{kbar}$.

Mössbauer experiments at $4.2 \mathrm{~K}$ in magnetic fields perpendicular to the $c$ axis were also carried out [46] : a splitting of the spectrum was observed, depending on 
the orientation of the field in the basal plane with a $60^{\circ}$ periodicity (Fig. 8). This result was interpreted in terms of shear strains leading to an asymmetrical canting of the sublattices [52].

Graphite-intec ralated $\mathrm{FeCl}_{2}$ [53], $\mathrm{FeCl}_{2}$ monolayers [55] and $\mathrm{Fe}(\mathrm{py})_{2} \mathrm{Cl}_{2}$ [48] were also studied; the latter exhibits a different point symmetry and a phase transition which does not change the orbital ground state.

4.2 Sulphospinels ( $\mathrm{FeCr}_{2} \mathrm{~S}_{4}$ AND DERIVATIVES). Early disagreement concerning cubic $\mathrm{FeCr}_{2} \mathrm{~S}_{4}[36 a, b]$ is now understood [56] as originating from sample preparation. By comparing $\mathrm{FeCr}_{2} \mathrm{~S}_{4}, \mathrm{CdCr}_{2} \mathrm{~S}_{4}$ [57] and $\mathrm{CoCr}_{2} \mathrm{~S}_{4}$ [58], Van Diepen and Van Stapele confirmed the magnetically induced character of the E. F. G. as claimed by Eibschütz [36b], and their crystal-field calculations very well accounted for the measured E. F. G. A cooperative distortion was observed at $13 \mathrm{~K}$ in $\mathrm{FeCr}_{2} \mathrm{~S}_{4}$; below this temperature, the spectra are very similar to those of $\mathrm{FeCr}_{2} \mathrm{O}_{4}$ which undergoes a cooperative Jahn Teller distortion [18]. Independently, Spender and Morrish [59] observed the same transition at $10 \mathrm{~K}$ (to my knowledge, $\mathrm{X}$-rays data do not exist). They observed that the E. F. G. in a random sample under applied field did not average to zero, thus ruling out an explanation based on crystallographic distortions above the cooperative distortion temperature; and the experiment should be repeated at lower temperature in order to check the static character of the distortion.

Crystal field calculations have been carried out of explain the magnetic anisotropy of $\mathrm{CdCr}_{2} \mathrm{~S}_{4}: \mathrm{Fe}^{2+}$ [60] and the optical absorption spectrum of $\mathrm{CdIn}_{2} \mathrm{~S}_{4}$ : $\mathrm{Fe}^{2+}[61]$; for the latter, vibronic effects in the excited $\Gamma_{5}$ are involved.

In addition, by varying the ratio $\mathrm{Fe} / \mathrm{Cr}$ in $\mathrm{FeCr}_{2} \mathrm{~S}_{4}$ [56], Lotgering and coworkers observed pair effects : the pair $\mathrm{Fe}^{2+}$ (tetra)- $\mathrm{Fe}^{2+}$ (octa) produces in tetrahedral site a large $\Delta E_{Q}$, accounted for by an orbital splitting of $\sim 120 \mathrm{~cm}^{-1}$ [62]. This value compares very well with the $\sim 100 \mathrm{~cm}^{-1}$ obtained by Imbert and coll. [35] for various pairs in $\mathrm{ZnS}$. Similarly, various pairs tetra-octa observed in spinels produce a large $\Delta E_{Q}$ in tetrahedral sites, while tetratetra pairs do not yield any sizeable effect [63]. According to these observations, the quadrupole interaction found in $\mathrm{FeAl}_{2} \mathrm{O}_{4}$ and $\mathrm{MgAl}_{2} \mathrm{O}_{4}$ [64] is due to inversion creating the pairs $\mathrm{Fe}^{2+}$ tetra- $\mathrm{Fe}^{2+}$ (or $\mathrm{Mg}^{2+}$ ) octa.

$\mathrm{MCr}_{2} \mathrm{O}_{4}$ and $\mathrm{MCr}_{2} \mathrm{~S}_{4}$ (Varret and coll. [10], Tanaka and coll. [107]) give spectra which are very similar to those of either $\mathrm{FeCr}_{2} \mathrm{O}_{4}$ or $\mathrm{FeV}_{2} \mathrm{O}_{4}$ previously studied (excepted $\mathrm{NiCr}_{2} \mathrm{O}_{4}$ which exhibits a large $H_{i}: 439 \mathrm{kOe}$ due to the magnetization of $\mathrm{Fe}^{2+}$ in a hard direction, §. 3.4).

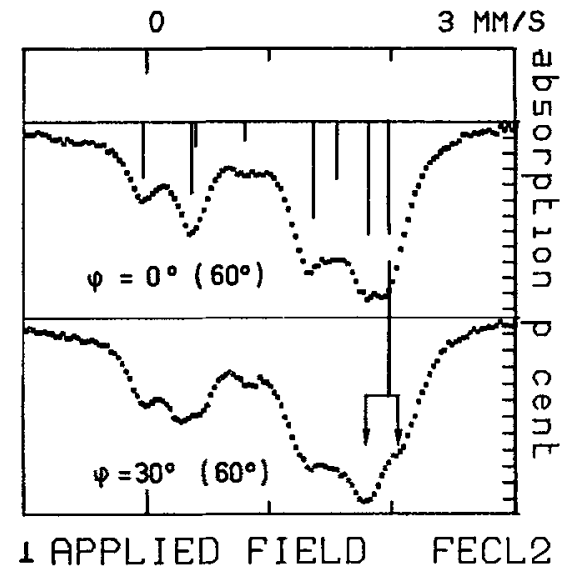

FIG. 9. - Shear strain effects : $\mathrm{FeCl}_{2}$ single crystal at $4.2 \mathrm{~K}$, submitted to a $50 \mathrm{kOe}$ field applied in the basal plane. $\varphi$ is the angle between $H_{\text {app }}$ and the $O x$ axis. The spectra show the superimposition of two different hyperfine patterns corresponding to different canting angles of the spins, which become equal for $\varphi=n(\pi / 3)[46]$.

4.3 ANTIFERRO-MAgNeTIC PEROVSKites. - Both quadrupole and magnetic interactions appear below the Néel temperature of $\mathrm{KFeF}_{3}(\sim 111 \mathrm{~K})$; a lower symmetry phase is present below $36 \mathrm{~K}$. The quadrupole interaction was first described as magnetically induced (Fatehally and coll. [66]). Taking advantage of the magneto-elastic character of the transition, Varret and Imbert [67] applied a (111) uniaxial stress to a single crystal platelet and removed the twinned structure of the crystal in the antiferro-magnetic phase ; this way, both the magnetostrictive distortion and the spin direction proved to lie in a (111) direction; the second transition temperature was found to depend on the twinned state of the crystal. A similar study was carried out by Ito [68].

A general interpretation involving both induced effects and a temperature-dependent axial crystal field was carried out by Davidson and coll. [69]. It is worth noticing that they observed narrow lines below $T_{\mathrm{N}}$, thus ruling out the intrinsic character of the previously reported critical superparamagnetism; this seems to be a general property for systems exhibiting broad lines just below $T_{\mathrm{N}}$, in view of similar observations by Wertheim or Pebler on $\mathrm{FeF}_{2}$ [70] and $\mathrm{FeF}_{3}[71,72]$ : line broadening in the vicinity of a transition temperature is finally attributed to structural imperfections of the sample.

$\mathrm{RbFeF}_{3}$ undergoes a cubic to tetragonal transition at $T_{\mathrm{N}} \sim 102 \mathrm{~K}$. Since there has been - to my knowledge - no experimental determination of the spin orientation, the sign of the gradient is not definitely established. A purely induced E. F. G., assumed in Wertheim's earlier work [36d] cannot be considered, because the lattice distortion is large. Therefore one must include a tetragonal crystal field in the calculations ; two possibilities, according to tables I and II, have to be examined : 
(i) The orbital ground state is $1 \pm 1>; \Delta E_{Q}$ (crystal field) is negative; the spin easy direction is $O z$, consequently $\Delta E_{Q}$ (induced) is expected to be negative too. These conclusions $\left(H_{i} \| O z, V_{z z}<0\right)$ cannot account for the observed spectra.

(ii) The orbital ground state is $(|2>-|-2>) / \sqrt{2}$, producing a positive $\Delta E_{Q}$ (crystal field). Because of the easy plane, the spin probably is perpendicular to $O z$, and an asymmetrical E. F. G. is to be expected. This situation differs from Davidson's suggestion [69] of a ground state $(|2>-|-2>) / \sqrt{2}$ and a spin in the $O z$ direction (which actually is a hard axis).

Further experimental work (determination of the spin direction, $\eta$-measurements) is needed to clarify the magnetic behaviour of $\mathrm{RbFeF}_{3}$. An involved model for this behaviour has been proposed by Goodenough and coll. [78].

4.4 MAGNETIC CHAINARS. - $\mathrm{RbFeCl}_{3}$ and $\mathrm{RbFeBr}_{3}$ are magnetic chainars compounds where $\mathrm{Fe}^{2+}$ is submitted to a trigonal crystal field. Different magnetic models have been proposed by Montano and coll. $\left(\mathrm{RbFeCl}_{3}\right.$ [75]), Eibschütz and Lines $\left(\mathrm{RbFeCl}_{3}-\right.$ $\left.\mathrm{RbFeBr}_{3}[76]\right)$ to account for the effect of magnetic intrachain interactions on the E. F. G. Both calculations were made assuming fast relaxation, and good agreement was obtained with quadrupole splitting and susceptibility data; there have been no Mössbauer experiments concerning the asymmetry parameter and the 3-dimension magnetically ordered phase.

$\mathrm{KFeCl}_{3}$ [74] was studied by Petrouleas and coll. from a different point of view : the paramagnetic data have been well explained by neglecting the magnetically induced effects; crystal field parameters have been determined (low symmetry). The dropping of induced effects was justified because the spin orbit and temperature reduction of $\Delta E_{Q}$ is not large ( $(3.2)$. The ground state wave function was determined and accounts for the measured $\eta$ and $H_{i}(4.2 \mathrm{~K})$. The low value obtained for $\lambda\left(\sim-58 \mathrm{~cm}^{-1}\right)$ has been recently explained by Hasselbach [77] in terms of molecular orbitals. In the vicinity of $T_{\mathrm{N}}$, broad Mössbauer lines are reported, and attributed to dynamical effects.

4.5 Carbonates. - Siderite $\left(\mathrm{FeCO}_{3}\right)$ has been extensively studied [44] because of its metamagnetic properties. The sign of $V_{z z}$ and $H_{i}$ have been measured, both are positive. A difficult problem arises from the presence of broad lines in the vicinity of $T_{\mathrm{N}}$ : by applying a $100 \mathrm{kOe}$ field along the easy axis of a single crystal, Forester and Koon [82] observed broad lines for the magnetic sublattice antiparallel to the applied field, but narrow lines for the sublattice parallel to the field ; they concluded that electronic relaxation was involved. The same conclusion was reached by H. N. Ok [81] for the system $\mathrm{CoCO}_{3}: \mathrm{Fe}^{2+}$. On the other hand, Nagy and Deszi [83] pointed out the influence of $\mathrm{Fe}^{3+}$ impurities upon the linewidths As a mat- ter of fact, natural siderite used by Forester and Koon contained up to 4.5 at $\% \mathrm{Mn}$ [82] ; these $\mathrm{Mn}$ impurities probably influence strongly the magnetic behaviour of the ferrous ion, and particularly deviate the spins of the antiparallel sublattice when the spin-flop field is approached. A field-aligned [32] synthetic powder, studied in a magnetic field parallel to the trigonal axis, might definitely solve this problem.

With the help of I. R. [84] and Raman [85] data, Spiering and coll. [79] determined the electronic level scheme of $\mathrm{Fe}^{2+}$ in siderite. They introduced a mixing parameter, $\theta \sim-1.2^{\circ}$, between the $\Gamma_{5}$ and $\Gamma_{3}$ states, according to the following ground state wave functions :

$$
\mid \varphi \pm>=\cos \theta t_{2 \mathrm{~g}}^{ \pm}+\sin \theta e_{\mathrm{g}}^{ \pm} .
$$

The value $\theta \sim-1.2^{\circ}$ compares well with that obtained considering the mixing parameter due to $B_{0}^{2}$. In the ${ }^{5} \mathrm{D}$ multiplet :

$$
\left|\varphi \pm>=\cos \theta^{\prime}\right| \pm 2> \pm \sin \theta^{\prime} \mid \mp 1>
$$

(according to [15], [18]).

Indentifying these expressions gives :

$$
\theta+\theta^{\prime}=\sin ^{-1}(1 / \sqrt{3}) \simeq 35^{\circ} 19^{\prime} .
$$

The relation of ref. [15] :

$$
\sin \theta^{\prime} \simeq(1 / \sqrt{3})(1+2 \delta / 3 A)
$$

becomes :

$$
\sin \theta \simeq-\delta / 3 \Delta \sqrt{2} \text {. }
$$

Using the values $\delta=1400 \mathrm{~cm}^{-1}, \Delta=10^{4} \mathrm{~cm}^{-1}$, the result $\theta=-1.9^{\circ}$ is obtained

The system $\mathrm{MnCO}_{3}: \mathrm{Fe}^{2+}$ with various iron concentrations has been carefully examined in the magnetically ordered region; all the results have been interpreted (Price and coll. [80]) by using an unique model including a single-ion anisotropy and the molecular field. The low value attributed to $\left\langle r_{Q}^{-3}\right\rangle Q$ $\left(6.45 \mathrm{~A}\right.$. U. b) yields a $\Delta E_{0}$ value $\sim 2.5 \mathrm{~mm} / \mathrm{s}$ which does not compare well with other ferrous systems; probably the value of $\delta / \lambda$ should be re-assessed $(\delta / \lambda \sim 3$ would not be unreasonable).

The diamagnetic systems $\mathrm{Zn}, \mathrm{Mg}, \mathrm{Ca}, \mathrm{CdCO}_{3}$ : $\mathrm{Fe}^{2+}$ (Price, Srivastava [129] exhibit slow relaxation spectra at low temperature ; in the case of $\mathrm{Ca}, \mathrm{Cd}$ carbonates, a small external magnetic field is needed to reveal the magnetic hyperfine structure (discussed in sec. V-5).

$4.6 \mathrm{Fe}\left(\mathrm{H}_{2} \mathrm{O}\right)_{6}^{2+}$ IN various Hosts. - The Mössbauer spectra of $\mathrm{Fe}^{2+}$ surrounded by six water molecules in different crystals, as well in ice [87] exhibit many similarities.

A great deal of work has been done on ferrous fluosilicate $\left(\mathrm{FeSiF}_{6}, 6 \mathrm{H}_{2} \mathrm{O}=\mathrm{Fe}-\mathrm{Fls}\right)$ [44] although the lattice symmetry of fluosilicates was not definitely determined. It is known now that $\mathrm{Fe}, \mathrm{Mg}, \mathrm{Mn}$-Fls undergo the $\mathrm{P} \overline{3} \mathrm{~m} 1 \leftrightarrow \mathrm{P} 2_{1} / \mathrm{c}$ transition, Co-Fls the $\mathrm{R} \overline{3} \leftrightarrow \mathrm{P} 2_{1} / \mathrm{c}$ 
transition, while Ni, Zn-Fls retain the R3 space group at all temperatures (see ref. in [88]). Recent work has been done on Fe-Fls by two independent groups. Spiering and coll. [89] used both EPR, NMR and Mössbauer spectra of powders in magnetic fields to determine the electronic level scheme. On the other hand, Varret and coll. [88] first determined $D$ and $\delta / \lambda$ at low temperature by means of pulsed magnetic field experiments [90], and $\eta$ from Mössbauer spectra of single crystals in applied fields [31] ; thereafter both $D$, $\delta / \lambda, \eta$ and the measured hyperfine anisotropy were used to determine the electronic level scheme; the latter agrees with EPR, NMR data, as well as with the temperature dependence of $\Delta E_{Q}$ below $50 \mathrm{~K}$; Mössbauer spectra of powders in magnetic fields can also be explained with the same set of parameters [34]. It is noteworthy that the independent results of the two groups compare well, except for the asymmetry parameter : $\eta_{\text {calc }}=0.16$ according to [89] against $\eta_{\text {mes }}=0.32 \pm 0.02$ according to [88]. To account for the large experimental $\eta$ value, Varret and coll. introduced a $\Gamma_{3}-\Gamma_{5}$ mixing through the 4 th order crystal field rhombic term; an alternative explanation would be the presence of a sizeable $\eta V_{z z}$ (latt). As a matter of fact, the mixing parameter $\left(\Gamma_{3}-\Gamma_{5}\right)$ reported by Spiering and coll., due to the $B_{2}^{0}$ and $B_{4}^{0}$ terms, $\theta \sim-3.2^{\circ}$, sizeably differs from the value $\theta \sim-1.9^{\circ}$ calculated with $B_{2}^{0}$ alone.

Interesting phenomena occur in the case of Fe-Fls : for instance temperature dependent crystal field [88] (in agreement with ESR data on the similar system $\mathrm{NiTiF}_{6}, 6 \mathrm{H}_{2} \mathrm{O}$ [91]), field dependent electronic relaxation [92] and proton motions (discussed in [88] and [92]).

Fluosilicates of $\mathbf{R} \overline{3}$ structure exhibit a smaller trigonal field $(\delta / \lambda \sim 2$, with the same sign as Fe-Fls [26]), but no relaxation effects [92].

The phase transition in Fe-Fls has been carefully observed by both groups [92, 93], who concluded that the axial crystal field remained unchanged through the $\mathrm{P} \overline{3} \mathrm{~m} 1 \leftrightarrow \mathrm{P} 2 / \mathrm{c}$ transition; this behaviour contrasts with that of the $\mathrm{R} \overline{3} \leftrightarrow \mathrm{P} 2_{1} / \mathrm{c}$ transition experienced by Co-Fls [92-94] ; there the axial field drastically changes in magnitude - not in sign.

Hexahydrated perchlorate, $\mathrm{Fe}\left(\mathrm{H}_{2} \mathrm{O}\right)_{6}\left(\mathrm{ClO}_{4}\right)_{2}$ exhibits at low temperature very similar spectra to those of $\mathrm{Fe}-\mathrm{Fls}$ and leads to almost identical determinations (Spiering and coll. [95]). A crystallographic transition is observed, associated with a reversal of the axial field term $[96,97]$. The same phenomenon is observed in the complex Fe-DCTU (Lattore and coll. [98]) and $\mathrm{M}\left(\mathrm{H}_{2} \mathrm{O}\right)_{6}\left(\mathrm{BF}_{4}\right)_{2}$ (Asch and coll. [99]).

Other hydrated complexes (Spiering, Deszi, Nagy [130]) and various heptahydrated sulphates (Spiering, Siebke [131]) have been investigated to obtain coherent sets of crystal-field parameters.

4.7 Miscellaneous. - Other compounds have been less extensively studied and we shall not discuss them in a detailed way. These systems are $\mathrm{Cu}_{2} \mathrm{FeGeS}_{4}$ [100], $\mathrm{MTiO}_{3}$ [101], $\mathrm{Fe}_{2} \mathrm{~F}_{5}, 7 \mathrm{H}_{2} \mathrm{O}$ [102] (which seems to exhibit a purely axial crystal field), $\mathrm{FeSiS}_{4}$ and $\mathrm{Fe}_{2} \mathrm{GeG}_{4}$ [128] and boracites of general formula $\mathrm{Fe}_{3} \mathrm{~B}_{7} \mathrm{O}_{13} \mathrm{X}$ [103] which undergo several phase transitions and already yield conflicting literature. The following studies involve pecularities that deserve a few comments :

$\mathrm{M}_{2} \mathrm{Mo}_{3} \mathrm{O}_{8}$ [14] : the ferrous ion has either tetrahedral or octahedral surroundings of oxygen but presents very similar temperature dependences of $\Delta E_{Q}$; this conflicts with expectations shown on figures 4,5 . To explain this similarity within a crystal field model, a large $\Gamma_{3}-\Gamma_{5}$ mixing through the 4th order axial crystal field term was needed : although the physical reason for the magnitude of this 4 th order term is not understood at the present time, the reported level scheme does not seem unreasonable since it accounts for the internal field experimental values - with the right sign. Magnetic measurements would be helpful in this case.

Various hexammines of general formula Fe $\left(\mathrm{NH}_{3}\right)_{6} \mathrm{X}_{2}$ have been studied by Asch and coll. [104]. All of them show an unsplit Mössbauer line at room temperature which requires fast reorientations of the $\mathrm{NH}_{3}$ molecules, in agreement with EPR observation. A phase transition was inferred from the splitting of the Mössbauer line. In most cases, a temperature dependent crystal field, attributed to proton motions, was needed to fit the quadrupole data.

5. Discussion. - There is now large amount of evidence to show that crystal-field theory may successfully fit the available data (Mössbauer, magnetic measurements, I. R., E. P. R., ...) in the case of a ionic bonding, i. e. in oxides, halogenides, sulfides.

5.1 SPIN-ORBIT COUPLING CONSTANT AND HYPERFINE PARAMETERs. - Because of covalency effects (see ref. in [6]), the orbital observables will have smaller values than in the free-ion. Using the notations of ref. [89], let

$$
\begin{aligned}
\mathbf{L}(x) & =x \mathbf{L} \text { (free-ion) } \\
\lambda & =k \lambda(\text { free-ion) }
\end{aligned}
$$

with $k, x<1$.

It is easily shown :

$$
\begin{aligned}
V_{i j}(\text { val }) & =\varkappa^{2} V_{i j}(\text { val })(\text { free-ion }) \\
H_{\mathrm{L}} & =\varkappa H_{\mathrm{L}} \text { (free-ion) } \\
H_{\mathrm{D}} & =\varkappa^{2} H_{\mathrm{D}} \text { (free-ion) }
\end{aligned}
$$

The relevant Mössbauer parameters are reduced in the following way :

$$
\begin{aligned}
\Delta E_{0} & =\varkappa^{2} \Delta E_{0}(\text { free-ion }) \simeq \varkappa^{2} \times 5 \mathrm{~mm} / \mathrm{s} \\
\left\langle r_{\mathrm{L}}^{-3}\right\rangle & =\varkappa<r_{\mathrm{L}}^{-3}>\text { (free-ion) } \\
& \simeq \varkappa \times 4.59 \text { A. U. [12] } \\
\left\langle r_{\mathrm{D}}^{-3}\right\rangle & =\varkappa^{2}<r_{\mathrm{D}}^{-3}>\text { (free-ion) } \\
& \simeq \varkappa^{2} \times 4.55 \text { A. U. [12] }
\end{aligned}
$$


and, via a screening mechanism

$$
A S=k^{\prime} A S \text { (free-ion) } \simeq k^{\prime} \times 550 \mathrm{kOe}[20] \text {. }
$$

For calculations using the non-reduced $\mathbf{L}$ operators, one must take :

$$
\begin{aligned}
& \lambda=k x \lambda_{0}=-k x \times 103 \mathrm{~cm}^{-1}|1 a| \\
& \rho=k^{\prime} x^{2} \rho_{0}=k^{\prime} x^{2} \times 0.95 \mathrm{~cm}^{-1}|22| .
\end{aligned}
$$

The separate observation of these reduction factors has not yet been carried out because of uncertainties due to additional contributions such as $V_{z z}$ (latt), supertransferred hyperfine field, interatomic dipolar magnetic field. Therefore one usually neglects the reduction of $\rho$, and uses the same value, $\left\langle r_{\mathrm{L}, \mathrm{D}}^{-3}\right\rangle$ for the dipolar and orbital contributions to $H_{i}$. Then four independent parameters are left : $\left\langle r_{\mathrm{L}, \mathrm{D}}^{-3}\right\rangle, A S$, $\Delta E_{0}, \lambda$.
Covalency of the ligands is supposed to have major influence on the isomer shift also. Therefore in table IV the results of recent works for the various hosts are given as function of the decreasing values of the isomer shift; octahedral and tetrahedral sites are given separately, because of their well-known difference in the $I . S$ values (see for instance ref. [14]).

Despite a large spread in the results, Table IV shows a general trend confirming the decrease in both parameters when covalency is increased : in the more ionic hosts, where the ferrous ion is surrounded by six $\mathrm{F}^{-}$or six $\mathrm{H}_{2} \mathrm{O}$, the reduction of the various parameters ranges between 0 and $\sim 10 \%$, while in the most covalent case reported $\left(\mathrm{CdCr}_{2} \mathrm{~S}_{4}\right.$ [57]) it amounts $\sim 40 \%$. The larger reductions in $\lambda$ observed in the case of dynamical Jahn-Teller effects are accounted for by vibronic effects $[23,73]$.

\section{Table IV}

Hyperfine parameters obtained from experimental measurements (underlined values had been fixed) ;

\begin{tabular}{|c|c|c|c|c|c|c|c|}
\hline Host & $\begin{array}{l}\text { I. S. } \\
\mathrm{mm} / \mathrm{s}\end{array}$ & $\begin{array}{c}\left\langle r_{\mathrm{L}, \mathrm{D}}^{-3}\right\rangle \\
\mathrm{A} . \mathrm{U} . \\
-\end{array}$ & $\begin{array}{l}A S \\
\mathrm{kOe} \\
-\end{array}$ & $\begin{array}{c}\Delta E_{0} \\
\mathrm{~mm} / \mathrm{s} \\
-\end{array}$ & $\mathrm{cm}^{-\lambda}$ & Réf. & Year \\
\hline Free-ion & & 4.6 & 550 & $\sim 5.0$ & 103 & [20a] & 1963 \\
\hline $\mathrm{KMgF}_{3}(*)$ & 1.41 & 4.1 & 495 & 4.8 & 60 & [73b] & 1972 \\
\hline $\mathrm{FeF}_{2}$ & 1.35 & 3.0 & 518 & 3.5 & 85 & {$[65]$} & 1970 \\
\hline $\mathrm{Fe}, \mathrm{Mn}, \mathrm{ZnF}_{2}$ & & 3.9 & 514 & - & - & [108] & 1972 \\
\hline $\mathrm{KFeF}_{3}$ & 1.33 & 3.2 & 580 & (2.4) & 50 & [69] & 1973 \\
\hline $\mathrm{FeSiF}_{6}, 6 \mathrm{H}_{2} \mathrm{O}$ & 1.28 & 4.5 & 540 & 4.8 & 97 & [89] & 1974 \\
\hline$\Gamma E I_{6}, O_{2}$ & - & 4.0 & 535 & 3.7 & 100 & [88] & 1975 \\
\hline $\mathrm{ZnSiF}_{6}, 6 \mathrm{H}_{2} \mathrm{O}$ & 1.26 & 3.7 & 535 & 4.0 & 88 & [88] & 1975 \\
\hline $\mathrm{Fe}\left(\mathrm{ClO}_{4}\right)_{2}, 6 \mathrm{H}_{2} \mathrm{O}$ & 1.27 & 4.4 & 550 & 4.35 & 95 & {$[95]$} & 1974 \\
\hline $\mathrm{FeSO}_{4}(* *)$ & 1.27 & 4.2 & 490 & 3.6 & 90 & [110] & 1976 \\
\hline $\mathrm{FeCO}_{3}$ & 1.24 & 4.6 & 480 & 4.2 & 102 & [79] & 1976 \\
\hline $\mathrm{MnCO}_{3}$ & - & 3.9 & 495 & $(2.5)$ & 89 & [80] & 1974 \\
\hline $\mathrm{CoCO}_{3}$ & - & - & - & (5.5) & $\sim 98$ & [81] & 1969 \\
\hline $\mathrm{KFeCl}_{3}$ & 1.14 & 2.7 & 300 & 3.2 & 58 & [74] & 1975 \\
\hline $\mathrm{Ge}(\mathrm{Fe}, \mathrm{Ni}, \mathrm{Co})_{2} \mathrm{O}_{4}$ & 1.10 & 4.2 & 500 & 3.1 & $\sim 80$ & {$[28]$} & 1974 \\
\hline$(\mathrm{Fe}, \mathrm{Ni}, \mathrm{Co}) \mathrm{Cl}_{2}$ & 1.10 & $4.3,-$ & 419,520 & $(5.5),(4.6)$ & 95,100 & {$[7,49]$} & 1966,68 \\
\hline $\mathrm{RbFeCl}_{3}$ & 1.09 & 一 & - & 4.3 & $7 \overline{8}$ & {$[75]$} & 1973 \\
\hline & - & - & - & - & 90 & [76] & 1975 \\
\hline $\begin{array}{l}\mathrm{MTiO}_{3} \\
\mathrm{Zn}_{2} \mathrm{Mo}_{3} \mathrm{O}_{8}\end{array}$ & 1.07 & - & - & 一 & $\sim 70$ & [101] & 1973 \\
\hline $\begin{array}{l}\mathrm{Zn}_{2} \mathrm{Mo}_{3} \mathrm{O}_{8} \\
\mathrm{MnO}, \mathrm{NiO}\end{array}$ & 1.07 & 4.0 & 500 & 3.4 & $\sim 100$ & [14] & 1972 \\
\hline $\mathrm{MnO}, \mathrm{NiO}$ & 1.05 & 4.6 & 458 & - & 67 & [19] & 1967 \\
\hline $\mathrm{MgO}(*)$ & 1.01 & 3.0 & 460 & 3,5 & 48 & [73a] & 1969 \\
\hline $\mathrm{CaO}\left(^{*}\right)$ (I. R. data) & 一 & - & - & - & 15 & {$[73 \mathrm{c}]$} & 1974 \\
\hline $\mathrm{FeBr}_{2}$ & 1.0 & $4.0,-$ & $390,-$ & $(5.0),(4.5)$ & $87, \underline{100}$ & {$[7,49]$} & 1969,68 \\
\hline $\mathrm{RbFeBr}_{3}$ & 一 & - & - & - & 80 & {$[76]$} & 1975 \\
\hline $\begin{array}{l}\mathrm{FeI}_{2} \\
\text { Tetrah. sites : }\end{array}$ & 0.85 & 3.3 & $345, \underline{515}$ & $(3.8),(4.2)$ & $73, \underline{100}$ & {$[7,49]$} & 1966,68 \\
\hline $\mathrm{Fe}_{2} \mathrm{Mo}_{3} \mathrm{O}_{8}$ & 0.97 & 4.0 & 460 & 3.4 & $\sim 100$ & [14] & 1972 \\
\hline $\mathrm{CdCr}_{2} \mathrm{~S}_{4}$ & 0.60 & 3.0 & $\overline{310}$ & 2.87 & 62 & [57] & 1972 \\
\hline
\end{tabular}
Values given in parentheses were not given, they have been deduced from the other data. Isomer shift refers to metallic iron and was measured at room temperature

(*) Dynamical Jahn-Teller effect. (**) M. O. calculations. 
More surprizing results are those of $\mathrm{KFeF}_{3}[69]$ and $\mathrm{KFeCl}_{3}$ [74], all the more in that the low value of $\lambda$ reported in the latter case has been explained by molecular orbital calculations including the spinorbit coupling of the ligand electrons [77].

At the present time it is not possible to extract further information about the covalency reductions from the available Mössbauer data. In particular, accurate correlations between the different reduction facters can by no means be obtained; as a crude approach, one might assume that all parameters are equally reduced by covalency effects.

Remark concerning the $\rho$ value: The value given by Pryce, $+0.95 \mathrm{~cm}^{-1}$ [22] was obtained from the departures from Landé intervals in the ${ }^{5} \mathrm{D}$ term. It has been shown by Trees [132] that Pryce's value accounts for both the true spin-spin interaction and the effects upon ${ }^{5} \mathrm{D}$ of the off-diagonal (inter-terms) spin-orbit coupling. Consequently: if the calculations would involve all spectroscopic terms together, one should use the pure spin-spin value, $\sim+0.18 \mathrm{~cm}^{-1}$, according to Watson and Blume's estimation [133]; on the other hand, when the calculations are restricted to the ${ }^{5} \mathrm{D}$ term, Pryce's value must be preferred.

5.2 Crystal-Field Coefficients. - An important point is the physical interpretation of the crystal field parameters $B_{n}^{m}$. They cannot be accounted for by point charge calculations [13] (which yield values about 4-5 times too small for the cubic term); this discrepancy is due to covalency effects. Consequently the $B_{n}^{m}$ are regarded as phenomenological parameters to be determined from experimental data. This difficulty is avoided by using molecular orbital models $[77,109]$, which have been applied to the case of $\mathrm{FeSO}_{4}(\mathrm{Zim}-$ mermann, Trautwein [110]) to explain the data concerning $V_{z z}, \eta$, magnetic susceptibility, as well as the magnitude and orientation of $H_{i}$.

Recent crystal-field determinations in $\mathrm{MTiO}_{3}$ (Ito, Morimoto [101]) and $(\mathrm{Ni}, \mathrm{Fe}) \mathrm{Cr}_{2} \mathrm{O}_{4}$ (Tanaka and coll. [107]) show a linear dependence of $\mathbf{B}_{2}^{0}$ upon $\mathrm{c} / \mathbf{a}$, thus giving a constant value to the ratio $\mathbf{B}_{2}^{0}(\exp ) / B_{2}^{0}$ (point-charge) in each series of compounds. It is probable that this ratio remains constant for different compounds if the 1st coordination shell remains the same. It would be interesting to compare the ratios $B_{n}^{m}$ (exp) $/ B_{n}^{m}$ (point charge) for different $n, m$, and to test the influence of symmetry. At the present time, there are few Mössbauer experiments dealing with this problem (furthermore, in many cases the crystallographic structure is not accurately established).

5.3 THE USE OF THE SPIN hamllonian. - Spin Hamiltonians are frequently used to interpret magnetic or EPR data at low temperature (see for instance ref. $[16,27,90,111])$ devoted to Fe-Fls). Somewhat surprisingly, the spin-Hamiltonian formalism is not extensively used in Mössbauer effect analyses dealing with the high spin ferrous ion, in contrast with studies on biomolecules where it has been often used [125].

The spin Hamiltonian expression suited for the case of an isolated orbital singlet obtained from 2 nd order perturbation of $\lambda \mathbf{L} . \mathbf{S}$, is the following :

$$
\mathfrak{H}_{S}=D S_{z}^{2}+E\left(S_{x}^{2}-S_{y}^{2}\right),
$$

to which a Zeeman term may be added. Thereafter, to account for the magnetic Mössbauer data, the magnetic hyperfine tensor formalism is used. This was done in the case of Fe-Fls (single-crystals $[45 a, 14 b]$ ), rubredoxin (powder [105]), and $\mathrm{FeL}_{4}\left(\mathrm{ClO}_{4}\right)_{2}$ (powder, [119]).

Nevertheless, the above expression for $\mathfrak{H}_{S}$ is rather crude, particularly when the ratio $\delta / \lambda$ is not large, and higher-order terms are to be included. Then $\mathfrak{H}_{S}$ may be expressed as a series of $\mathrm{O}_{n}^{m}$ operators acting on the spin [112], for which the symmetry rules given in ref. [10] apply. The pulsed-field data on Fe-Fls [90] enabled Rudowicz $[112,113]$ to determine the 2 nd and 4 th order axial terms of $\mathfrak{H}_{S}$, in qualitative agreement with the expectation values arising from perturbation calculations of $\lambda \mathbf{L} . \mathbf{S}$ developed to the 4 th order (whose expressions are given in [113]). To account for magnetic Mössbauer data with the highorder $\mathfrak{H}_{S}$ would probably require an improved hyperfine tensor (the corresponding high-order perturbation calculations have not yet been done).

Another interesting case is that of the well-isolated spin triplet occuring in the case of $\mathrm{FeCl}_{2}$ (7) (this is a pecularity of the level scheme when $\delta<5 \lambda$ ). A fictitious spin $S=1$ was used to account for the magnetic measurements reported in $\S 4.1$. The hyperfine tensor approximation should be somewhat crude in the case of $\mathrm{FeCl}_{2}(\delta \sim \lambda)$, but should be rather good for $\delta / \lambda \sim 5$, for which the spin triplet remains isolated enough.

As a general remark, the use of both spin hamiltonian and hyperfine tensor formalism should allow a simple interpretation of the Mössbauer spectra of powdered paramagnets in applied fields. This method might compete with methods recently developed, using either an empirical description of the anisotropic magnetization of the ferrous ion in low or high fields (Varret [34]), or the complete assessment of the crystalfield model (Spiering and coll. [89]) ; this method using both spin Hamiltonian and hyperfine tensor has already been applied to the case of $\mathrm{FeL}_{4}\left(\mathrm{ClO}_{4}\right)_{2}$ [119] for which the complete electronic scheme is not known.

5.4 THE CASE OF FLUCTUATING SURROUNDINGS. -In some cases, the assumption of a time independent crystal-field may not be valid, because of the following mechanisms :

Electron-hopping, which may occur either suddenly, associated with a phase transition (Verwey transition of $\mathrm{Fe}_{3} \mathrm{O}_{4}$ ), or smoothly, leading to a progressive change in both the isomer shift and the quadrupole 
interaction. In the latter case (Gérard and Grandjean [114]) asymmetrical spectra are to be expected.

Conformational excitation : to our knowledge, this phenomenon has not yet been observed with ferrous ionic compounds. However it is clearly responsible for the thermal dependence of $\Delta E_{Q}$ in the ferric compound $\mathrm{BaFe}_{12} \mathrm{O}_{19}$ (Kreber and coll. [115]). In Hemoglobin model also (Spartalian and coll. [116]) the symmetrical broadening of the quadrupole lines is explained in terms of conformational excitation.

Hindered rotations : Fast re-orientations of the $\mathrm{NH}_{3}$ molecules are responsible for the removal of the quadrupole interaction in cubic hexammines at room temperature (Asch and coll. [104]). Symmetrical broadening reported in the Si-pentadienyliron complex (Sawai and coll. [117]) is attributed to a slowing down of the rotation around the Fe-Si bond. Similar phenomena are also reported in the Mössbauer spectra of a thiourea-ferrocene clathrate (Gibb [118]) and attributed to relaxation between inequivalent positions of the ferrocene molecule. Symmetrical broadening also observed in Zinc-fluosilicate (Jehanno and Varret, unpublished results) is likely to originate from water molecule rotations.

In all these cases, to account for the thermal dependence of $\Delta E_{Q}$ the usual crystal-field model does not apply. Nevertheless, an average, temperature dependent, crystal field may be used when the following requirements are fulfilled :

(i) isomer shift independent of the involved motions ;

(ii) fast fluctuations or small effect of the fluctuations upon the E. F. G.

An obvious reason for the crystal-field to be temperature-dependent is the lattice thermal expansion.This is often encountered in E. P. R. studies [86] and leads to crystal-field variations by some \%, fully negligible in most of Mössbauer analyses.

Therefore an interpretation of Mössbauer data in terms of temperature-dependent crystal-field has to be supported by the separate observation of fluctuating surroundings ; this was done by EPR, NMR, or X-ray measurements in the cases presently reported, and a qualitative agreement was found. A quantitative agreement might be obtained if the same paramagnetic ion was observed by both Mössbauer and EPR techniques; such a combined study has not yet been performed, to our knowledge.

Another case for which the assumption of a temperature-independent crystal-field is not valid, is obviously the high-spin low-spin transition occuring in Phenanthroline and derivatives [126]. We do not discuss this point.

Figure 10 shows the thermal dependence of the axial orbital splitting needed to fit the quadrupole data on fluosilicates ([88] and previous works): the low-temperature level scheme, carrefully determined with the help of pulsed-field data, does not account for the high-temperature quadrupole data. Following the present analysis, the assumed temperature dependence of the crystal-field might be attributed to water molecule motions which have been observed by NMR [127].
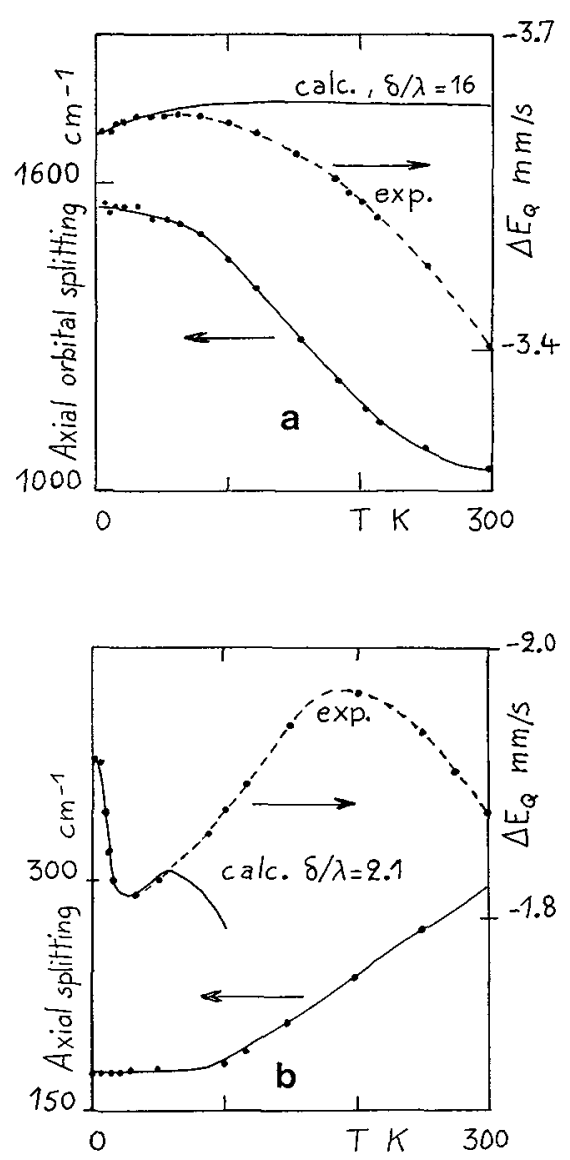

FIG. 10. - Temperature-dependent crystal field in Fe-Fls (a) and $\mathrm{Zn}-\mathrm{Fls}(b)$ [88]. The calculated variations of $\Delta E_{Q}$ correspond to the low-temperature determinations of the crystal field.

5.5 Slow RelaXation IN PARAmagnets. - Usually the electronic relaxation rates of paramagnetic $\mathrm{Fe}^{2+}$ are fast compared to the nuclear precession rates ; therefore the thermal averages used in sec. 3 to calculate the hyperfine interactions are usually meaningful.

Nevertheless the assumption of fast electronic relaxation appeared to be irrelevant in some cases : this was firstly discovered in $\mathrm{FeL}_{4}\left(\mathrm{ClO}_{4}\right)_{2}$ (Zimmermann and coll. [119]) : a small magnetic field (10 kOe at $4.2 \mathrm{~K}$ ) was able to develop the full magnetic hyperfine structure and gave narrow lines, in conflict with expectations from the fast relaxation model. Figure 11 illustrates the development of the magnetic hyperfine structure in small applied fields.

Further examples of slow relaxation were recently given : $\mathrm{Fe}$ (papt) ${ }_{2} \mathrm{C}_{6} \mathrm{H}_{6}$ (Zimmermann and coll. [120]), $\mathrm{Fe}^{\mathrm{II}}$ acetylacetonates (Nicolini and coll. [121]), Ferrous fluosilicate (Chappert and coll. [92]), carbo- 
nates (Price and coll. [129]), $\mathrm{ZnF}_{2}$ (Frankel and coll. [108b]), and various compounds [122]. By comparing these studies, the following conclusions may be already obtained :

i) All concerned compounds are magnetically diluted (paramagnets) ; consequently, only the spin-

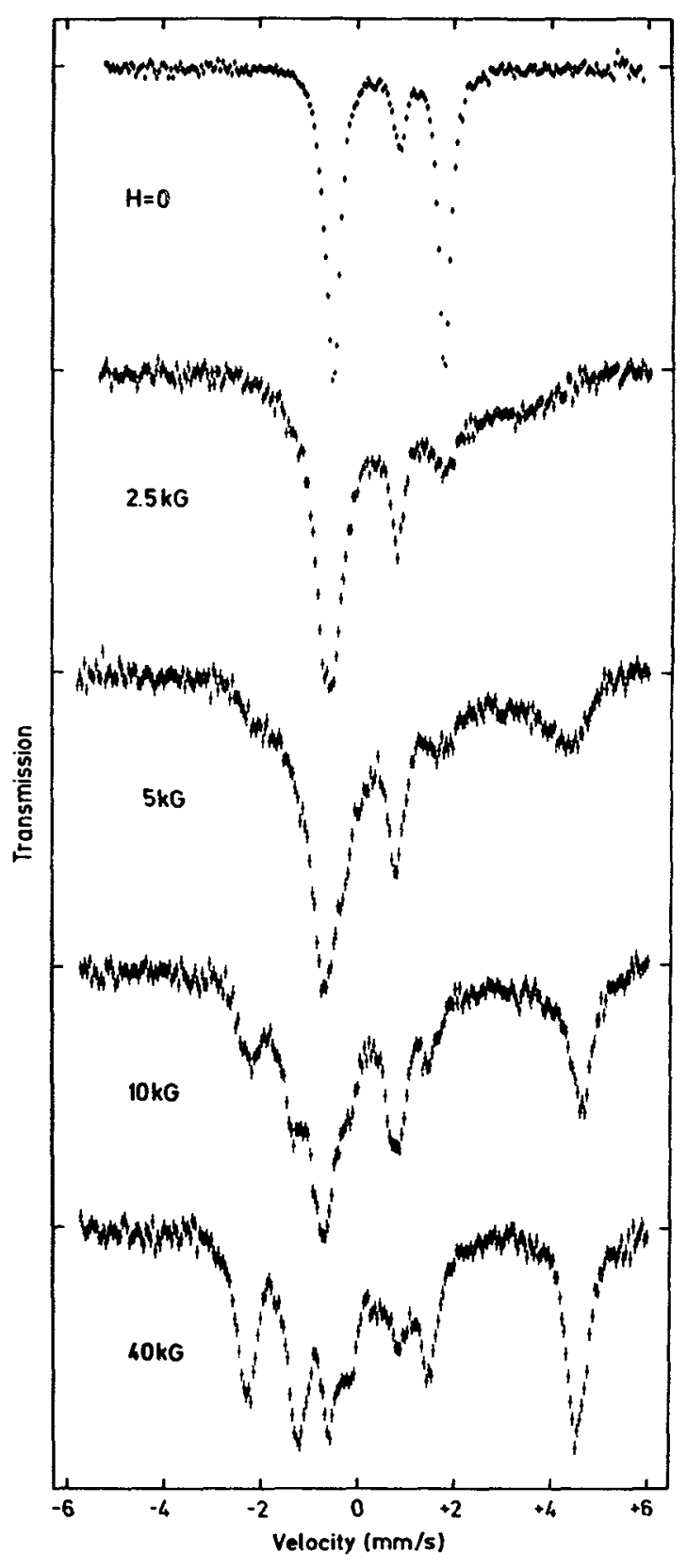

Fig. 11. - Field revealed slow relaxation in Fe(papt) ${ }_{2} \mathrm{C}_{6} \mathrm{H}_{6}$ [120].

lattice relaxation occurs. This can be checked by studying samples containing $\mathrm{Fe}^{2+}$ at various concentrations.

ii) In zero external field, at low temperature, the electronic relaxation is slow. In the case of a true ground spin doublet, the magnetic hyperfine structure is observed $\left(\mathrm{ZnCO}_{3}\right)$; in the case of a quasi-doublet whose splitting is larger than the hyperfine coupling, the magnetic hyperfine structure is not observed (because of the diamagnetic character of the spin singlets). In the case of a ground spin singlet these effects are observed at finite temperature only [92].

iii) Applying a small magnetic field induces a magnetic component to the spin levels; accordingly the magnetic hyperfine structure may be observed. The external field acts in an anisotropic way : this has been observed in powder samples (Zimmermann and coll. $[119,120])$ as well as in single crystals (ferrous fluosilicate [92]).

iv) Excited orbital levels are expected to contribute to the relaxation rate. The failure to observe relaxation phenomena in various diamagnetic hosts : $\mathrm{MgCl}_{2}$ [7], $\mathrm{Zn}_{2} \mathrm{Mo}_{3} \mathrm{O}_{8}$ [14], $\mathrm{ZnSiF}_{6}, 6 \mathrm{H}_{2} \mathrm{O}$ [92], is probably due to the presence of low-lying orbital excited levels,

5.6 OTHER METHODS. - The validity of the crystal field method presently developed is limited to the case of mainly ionic bonding, when the crystal field is weak, so that Hund's rule holds. When these conditions are not fulfilled, which usually happens with organic compounds, other methods must be used to correctly describe the electronic properties of the iron ion. These methods are based on molecular orbital calculations [109, 110, 123] as well as configuration interaction [124]. A nice evidence for the usefulness of M. O. calculations was given by $\mathrm{Fe}^{2+}$ in ferrocene (Collins [123]) for which the crystal-field calculations gave the wrong sign to the main component of the E. F. G.

6. Conclusion. - When the ionic character of the bonding is strong enough, the crystal field model may be a powerful tool to describe and explain both the Mössbauer spectra, the magnetic and spectroscopic data concerning the high-spin ferrous ion. Confident assessment of the involved parameters is obtained as soon as various data are taken into account. The physical meaning of the values given to these parameters is not always obvious ; therefore series of isostructural compounds should be more systematically studied.

It is expected that the temperature dependence of the crystalline field, due to the motions of light atoms in the lattice, will be extensively studied.

In addition, the slow electronic relaxation of the ferrous ion located in a diamagnetic host might be observed in further cases.

Acknowledgments are due to the many authors who sent reprints or preprints of their recent work concerning crystal-field effects, to F. Hartmann-Boutron and $H$. Spiering for suggestions and critical reading of the manuscript. 


\section{References}

[1] Low, W., Paramagnetic Resonance, Sol. State Physics 2 (1960).

Abragam, A., Bleaney, B., Electron Paramagnetic Resonance, ed. Marshall and Williamson (Clarendon Press, Oxford).

Goodenough, J. B., Magnetism and The Chemical Bond. KANAMORI, J., in Magnetism, ed. Rado and Suhl.

[2] Abragam, A., Boutron, F., C. Rend. Hebd. Sean. Acad. Sci. 252 (1961) 2404.

[3] Johnson, C. E., Marshall, W., Perlow, G. J., Phys. Rev. 126 (1962) 1503.

[4] Okiri, A., Kanamori, J., J. Phys. Soc. Japan 19 (1964) 908.

[5] Ono, K., Ito, A., J. Phys. Soc. Japan 19 (1964) 899.

[6] Ingalis, R., Phys. Rev, 133A (1964) 787.

[7] Ono, K., Iтo, A., FuנIta, T., J. Phys. Soc. Japan 19 (1964) 2119.

Fujita, T., Ito, A., Ono, K., J. Phys. Soc. Japan 21 (1966) 1734, 27 (1969) 1143.

[8] Eicher, H., Z. Phys. 171 (1963) 582.

[9] Stevens, H. W. K., Proc. Phys. Soc. A 65 (1952) 209.

[10] Boutron, F., Saint-JAmes, D., Rapport CEA, no 1952 (1961)

[11] Hutchings, M. T., Solid State Phys. 16 (1964) 227.

[12] Freeman, A. J., Watson, R. E., Phys. Rev. 131 (1963) 2566.

Sternheimer, R. M., Phys. Rev. 130 (1963) 1423.

InGaLls, R., Phys. Rev. 128 (1962) 1155.

[13] OWen, J., Thornley, J. H. M., Repts Prog. Phys. 29 (1966) 673.

[14] Varret, F., Czeskleba, H., Hartmann-Boutron, F., IMBERT, P., J. Physique 33 (1972) 54.

VARRET, F., Thesis (unpublished) Paris VI (1972).

[15] Varret, F., Hartmann-Boutron, F., Ann. Phys. 3 (1968) 157.

[16] Palumbo, D., Nuovo Cimento 8 (1958) 271.

[17] Low, W., Weger, M., Phys. Rev. 118 (1960) 1119.

[18] Hartmann-Boutron, F., Imbert, P., J. Appl. Phys. 39 (1968) 775 .

[19] Siegwarth, J. D., Phys. Rev. 155 (1967) 285.

[20] Freeman, A. J., Watson, R. E., Phys. Rev. 127 (1962) 2058.

[21] Marshall, W., Johnson, C. E., J. Physique Radium 23 (1962) 733

[22] Pryce, M. H. L., Phys. Rev. 80 (1950) 1107.

[23] Ham, F. S., J. Physique Colloq. 35 (1974) C 6-121.

[24] Gandel, U., Chem. Phys. Letters 4 (1969) 87.

[25] Zimmermann, R., Spiering, H., Phys. Stat. Sol b 67 (1975) 487.

[26] Varret, F., Danon, I., Chem. Phys. Lett. 20 (1973) 538.

[27] Rubins, R. S., Proc. Phys. Soc. 80 (1962) 244 ; Bull. Am. Phys. Soc. 14 (1969) 1183.

[28] Varret, F., Imbert, P., J. Phys. Chem. Solids 35 (1974) 215.

[29] Ingalls, R., Ono, K., Chandler, L., Phys. Rev. 172 (295) 1968.

[30] ZORY, P., Phys. Rev. 140A (1965) 1401.

[31] Varret, F., Jehanno, G., J. Physique Colloq. 35 (1974) C 6-639.

[32] Nagy, D. L., Kulcsar, K., Ritter, G., Spiering, H., Vogel, H., Zimmerman, R., Deszi, I.,PARdAVI-HoRvath, M., J. Phys. Chem. Solids 36 (1975) 759.

[33] Gabriel, J. R., RubY, S. L., Nucl. Inst. Methods 36 (1965) 23.

Collins, R. L., Travis, J. C., Mössbauer Effect Methodology 3 (1967) 123.
[34] Varret, F., J. Phys. Chem. Solids 37 (1976) 265.

[35] Gérard, A., Imbert, P., Prange, H., Varret, F., WinTenberger, M., J. Phys. Chem. Solids 32 (1971) 2091.

[36] Hoy, G. R., Singh, K. P., Phys. Rev. 172 (1968) 514.

Exbschutz, M., Shtrikman, S., Tenenbaum, Y., Phys. Lett. 24 (1967) 563.

Ganiel, U., Shtrikman, S., Phys. Rev. 167 (1968) 258.

Wertheim, G. K., Guggenheim, H. J., Willlams, H. J., Buchanan, D. N. E., Phys. Rev. 158 (1967) 446.

[37] Kamal, R., Mendiratta, R. G., Phys. Rev. B 3 (1971) 1649.

[38] Ray, T., Regnard, J. R., Phys. Rev. B (May 1976).

Regnard, J. R., J. Physique Colloq. 35 (1974) C 6-181, Int. Conf. Mössbauer Effect (Cracow 1965).

[39] Eibschütz, M., Davidson, G. R., Guggenheim, H. J., Phys. Rev. B 9 (1974) 3885.

[40] Artman, J. O., Muir, A. H. Jr, Wiedersich, H., Phys. Rev. 173 (1968) 337.

[41] Abeledo, C. R., Frankel, R. B., Misetich, A., Blum, N. A., J. Appl. Phys. 42 (1971) 1723.

[42] Simkin, D. J., Phys. Rev. 177 (1969) 1008.

[43] Cosgrove, J. G., Collins, R. L., J. Chem. Phys. 55 (1971) 4238.

Takashima, Y., Maeda, Y., NaKaYama, Y., Kyushu University Memoirs, Series C, Chemistry Vol. 7, No 1.

[44] Greenwood, N. N., Gibn, T. C., Mössbauer Spectroscopy (ed Chapman \& Hall. London) 1971.

[45] Johnson, C. E., Proc. Phys. Soc. 92 (1967) 748.

Hazony, Y., Phys. Rev. B 3 (1971) 711.

[46] NASSER, J. A., VARret, F., Int. Conf. Magn. and Magnetic Materials, AIP Conference Proceedings 24 (1975) 59.

[47] Nasser, J. A., VARret, F., Solid State Commun. 13 (1973) 381.

[48] ReifF, W. M., Franket, R. B., Little, B. F., Long, G. J., Chem. Phys. Lett. 98 (1974) 68

SAnchez, J. P., Asch, L., Friedt, J. M., Chem. Phys. Lett. 18 (1973) 250.

[49] Pfletschinger, E., Z. Phys. 209 (1968) 119.

Hazony, Y., OK, H. N., Phys. Rev. 188 (1969) 591.

[50] Carrara, P., Thesis, Orsay (1967).

Lanusse, M. C., Carrara, P., Fert, A. R., Mischler, G., Redoules, J, P., J. Physique 33 (1972) 429.

[51] Hamman, J., Nasser, J. A., Phys. Stat. Solid. (b) 56 (1973) 95.

[52] NASSER, J. A., Thesis, Orsay (1973).

[53] Stukan, R. A., Pruskov, V. A., Novikov, Y. N., VolPIN, M. E., GoldaNSKI, V. I., Zhrunal Strukturnoi Khimii 12 (1971) 622.

[54] Perkins, H. K., Hazony, Y., Phys. Rev. B 5 (1972) 7.

[55] Shechter, H., Dash, J. B., Mor, M., Ingalls, R., Buskshrpan, S., Phys. Rev. (to appear, 1976).

[56] Lotgering, F. K., van Diepen, A. M., Olijhoek, J. F., Solid State Commun. 17 (1975) 1149.

Van Diepen, A. M., Lotgering, F. K., Olijkoek, J. F., $J$. of Magnetism and Magnetic Materials 3 (1976).

[57] Van Diepen, A. M., van Stapele, R. P., Phys. Rev. B 5 (1972) 2462.

[58] Van Diepen, A. M., van Stapele, R. P., Solid State Commun. 13 (1973) 1651.

[59] Spender, M. R., Morrish, A. H., Can J. Phys. 50 (1972) 1125, Solid State Commun. 11 (1972) 1417.

[60] Hoekstra, B., van Stapele, R. P., Voermans, A. B., Phys. Rev. B 6 (1972) 2762.

[61] Wittekoek, S., van Stapele, R. P., Wijma, A. W. J., Phys. Rev. B 7 (1973) 1667. 
[62] Van Diepen, A. M., Private commun.

[63] IMBert, P., Private commun.

[64] Ono, K., Ito, A., Syono, Y., Phys. Lett. 19 (1966) 620

[65] Johnson, D. P., Ingalls, R., Phys. Rev. B 1 (1970) 1013.

[66] Fatehally, R., Sastry, N. P., Nagarajan, R., Phys. Stat. Solids 26 (1968) 91.

[67] Varret, F., Imbert, P., Phys. Stat. Sol. B 56 (1973) 127.

[68] Iтo, A., Morimoto, S., 5th Int. Conf. Mössbauer Spectroscopy (Bratislava 1973) p. 166.

[69] Davidson, G. R., Eibschutz, M., GugGenheim, H. J., Phys. Rev. B 8 (1973) 1864.

[70] Wertheim, G. K., Buchanan, D. N. E., Phys. Rev. 161 (1967) 478

[71] Wertheim, G. K., GUGGenheim, H. J., BuchANAN, D. N. E., Phys. Rev. 169 (1968) 465.

[72] Pebler, J. W., Richter, F. W., Z. Phys. 221 (1969) 480.

[73] Frankel, R. B., Chappert, J., Regnard, J. R., MiseTICH, A., ABELEDO, G. R., Phys. Rev. B 5 (1972) 2469.

Chappert, J., Frankel, R. B., Misetich, A., Blum, N. A., Phys. Rev. 179 (1969) 578.

Regnard, J. R., Chappert, J., RibeYron, A., Solid Stat. Commun. 15 (1974) 1539.

[74] Petrouleas, V., Kostikas, A., Simopoulos, A., Phys. Rev. B 12 (1975) 4666, 4875.

[75] Montano, P. A., Cohen, E., Shbchter, H., Phys. Rey. B 7 (1973) 1180.

[76] Eibschutz, M., Lines, M. E., Sherwood, R. C., Phys. Rev. B 11 (1975) 4595

Lines, M. E., Eibschutz, M., Phys. Rev. B 11 (1975) 4583.

[77] Hasselbach, K. M., Chemical Society Mössbauer Spectroscopy Discussion Group (Liverpool, 12-13 July 1976).

[78] Goodenough, J. B., Menyuk, N., Dwight, K., KafaKAS, J. A., Phys. Rev. B 2 (1970) 4640

[79] SpIERING, H., NAGy, D. L., ZimmermanN, R., submitted to J. Chem. Phys.

[80] Price, D. C., MaArtense, I., Morrish, A. M., Phys. Rev. B 9 (1974) 281

[81] Hang Nam OK, Phys. Rev. 181 (1969) 563.

[82] Forester, W., Koon, N. C., J. Appl. Phys. 40 (1969) 1316.

[83] NagY, D. L., Deszi, I., Solid State Comm. 12 (1973) 749.

[84] Prinz, G. A., Forester, D. W., LeWIs, J. L., Phys. Rev. B 8 (1973) 2155.

[85] Popkov, Y. A., Eremrnko, V. V., Fomm, V. I., MoKHIR, A. P., Sov. Phys. Solid State 14 (1973) 1985.

[86] Serway, R. A., Phys. Rev. B 3 (1971) 608.

[87] Nozik, A. J., Kaplan, M., J. Chem. Phys. 47 (1967) 2960.

[88] Varret, F., Jehanno, G., J. Physique 36 (1975) 415.

[89] SpIering, H., ZimmermanN, R., RitTer, G., Phys. Stat. Solidi b 62 (1974) 124.

[90] Varget, F., J. Phys. Chem. Solids 37 (1976) 257.

[91] Rubins, R. S., Griffin, B. C., Burris, R., J. Chem. Phys. 64 (1976) 3349.

[92] Chappert, J., JehanNo, G., VarRet, F., this conference.

[93] SPIERING, H., private commun.

[94] Jodrn, Ph., Thèse $3^{\text {e }}$ cycle, Univ. Louis Pasteur, Strasbourg, France (1974).

[95] Spiering, H., NaGy, D. L., ZimmermanN, R., J. Physique Colloq. 35 (1974) C6-231.

[96] Coey, J. M. D., Deszi, I., Thomas, P. M., Ouseph, P. J., Phys. Lett. 41A (1972) 125.

[97] Reiff, W. M., Frankel, R. B., Abeledo, C. R., Chem. Phys. Lett. 22 (1973) 124.

[98] Latorre, R., Abeledo, C. R., Frankel, R. B., Costamagna, J. A., Reiff, W. M., Frank, E., I. Chem. Phys. 59 (1973) 2580.
[99] Asch, L., Deszi, I., Lohner, T., Molnar, B., Chem. Phys. Lett. 39 (1976) 177.

[100] Exbschutz, M., Hermon, E., Shtrukman, S., J. Phys. Chem. Solids 28 (1968) 1633.

Imbert, P., VARret, F., Wintenkerger, M., J. Phys Chem. Solids 34 (1973) 1675.

[101] Iтo, A., Morimoto, S., 5th Int. Conf. Mössbauer Spectroscopy, Bratislava (1973) p. 161.

[102] Imbert, P., Jehanno, G., Macheteau, Y., Varret, F., J. Physique 37 (1976) 969.

[103] Trooster, J. M., Phys. Stat. Solids 32 (1969) 179.

Pisarev, R. V., Druzhinin, V. V., Nesterova, N. N. Prochorova, S. D., Andreeva, G. T., Phys. Stat. Solidi 40 (1970) 503.

Pylnev, V. G., Belov, V. F., Zheludev, I. S., KorNEEv, E. V., Belov, A. F., Fiz. Tverd. Tela 16 (1974) 2774.

Link, R., Wurtinger, W., J. Physique Colloq. 35 (1974) C 6-581.

Pylnev, V. G., Chukovskir, F. N., Zheludev, I. S., Int. Conf. Mössbauer Spectroscopy, Cracow (1975) p. 265.

[104] Asch, L., Shenoy, G. K., Friedt, J. M., Adloff, J. P., J. Chem. Phys. 62 (1975) 2335 and J. C. S. Dalton (1975) 1235

[105] Petrouleas, V., Simopoulos, A., Kostikas, A., This Conference.

[106] Varret, F., Gérard, A., Hartmann-Boutron, F., Imbert, P., Kleinberger, R., Int. Conf. Appl. Mössbauer Effect, Tihany (1969).

[107] Tanaka, M., Tokoro, T., Morr, T., 5th Int. Conf. Mössbauer Spectroscopy, Bratislava (1973) p. 118.

[108] Abeledo, C. R., Frankel, R. B, Misetich, A., Chem., Phys. Lett. 14 (1972) 561, 31 (1975) 108.

[109] Trautwein, A., Report KURRI-TR-141 (Kyoto University, 1975) and ref. therein.

[110] Zimmermann, R., Trautwein, A., Harris, E. F., Phys. Rev. B 12 (1975) 3902.

Trautwein, A., Zimmermann, R., Phys. Rev, B 13 (1976) 2238.

[111] Ohtsuka, T. I., J. Phys. Soc. Japan 14 (1959) 1245.

JACKson, K. C., Phil. Mag. 4 (1959) 269.

[112] Rudowicz, C., Acta Physica Polonica A 47 (1975) 291, 305.

[113] Rudowrcz, C., Sol. State. Commun. 15 (1974) 1937.

[114] Gérard, A., Grandjean, F., J. Phys. Chem. solids 36 (1975) 1365.

Grandjean, F., Gérard, A., Solid State Commun. 16 (1975) 553.

[115] Kreber, E., Gonser, j., Trautwein, A., Harris, F. E., 5th Int. Conf. Mössbauer Spectroscopy, Bratislava (1973) p. 130.

[116] Spartalian, K., Lang, G., Collman, J. P., Gagner, R. P., ReEd, C. A., J. Chem. Phys. 63 (1975) 5375.

[117] Sawai, T., Martin, J. P., Butler, I. S., Simkin, D., J. Physique Colloq. 35 (1974) C 6-247.

[118] Gibs, T. C., Mössbauer Effect Disc. Group Meeting, Liverpool (1976) and J. Phys. C (1976) 2627.

[119] ZimmermanN, R., Spiering, H., RitTer, G., J. Chem. Phys. 4 (1974) 133 and 5th Int. Conf. Mössbauer Spectroscopy, Bratislava (1973) p. 477.

[120] Z.mmermanN, R., RItTer, G., SPiering, H., NAGY, D. L., J. Physique Colloq. 35 (1974) C 6-439 and Int. Conf. Mössbauer Spectroscopy, Cracow (1975) p. 401.

[121] Nicolini, C., Mathieu, J. P., Chappert, J., this conference.

[122] Sampers, J., Trooster, J. M., Int. Conf. Mössbauer Spectroscopy, Cracow (1975) p. 417. 
[123] Collins, R. L., J. Chem. Phys. 42 (1965) 1072.

Dahl, J. P., Ballhausen, C. F., Mat. Fys. Medd. Dan. Vid. Selsk., 33 (1961) no 5.

[124] Eicher, H., Bade, D., Parak, F., J. Chem. Phys. 64 (1976) 1446.

[125] Munck, E., Champion, P. M., J. Physique Colloq. 35 (1974) C 6-33.

[126] Konig, E., Riter, G., Mössbauer Effect Methodology 9 (1975) p. 3.

Fleisch, J., Gutlich, P., Hasselbach, K. M., MulLER, W., J. Physique Colloq. 35 (1974) C 6-659.

[127] SkJaeveland, S. M., Svare, I., Phys. Script. 10 (1974) 273.
[128] Meyer, C., Gros, Y., Vincent, H., Solid State. Commun. 16 (1975) 625.

Meyer, C., Gros, Y., Vincent, H., Bertaut, E. F., $J$. Phys. Chem. Sol. (to appear).

[129] Price, D. C., Srivastava, K. K. P. J. Physique Colloq. 37 (1976) C6-123.

[130] Spiering, H., Deszi, I., NAGy, D. L., J. Physique Colloq. 37 (1976) C6.

[131] Siebke, W. SpIERING, H., J. Physique Colloq. 37(1976) C6. [132] Trees, R. E., Phys. Rev. 82 (1951) 683.

[133] Watson, R. E., Blume, M., Phys. Rev. 139A (1965) 1209. 